
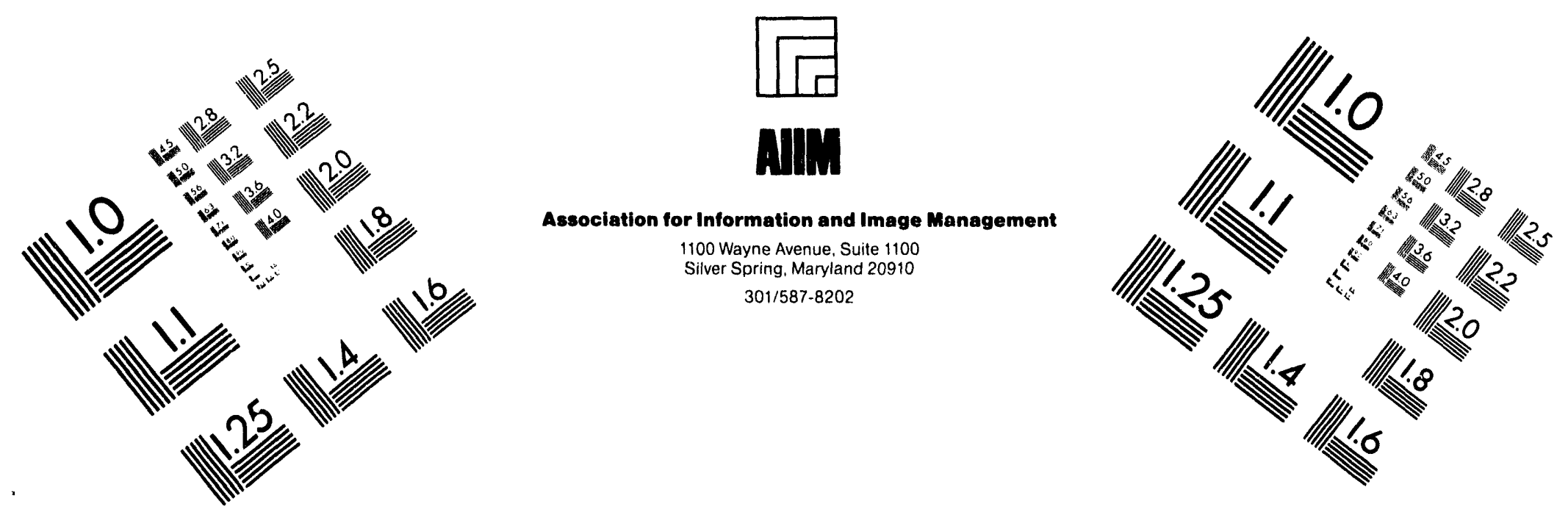

\title{
Centimeter
}

$\begin{array}{llllllllllllllll}1 & 2 & 3 & 4 & 5 & 6 & 7 & 8 & 9 & 10 & 11 & 12 & 13 & 14 & 15 & \mathrm{~mm}\end{array}$

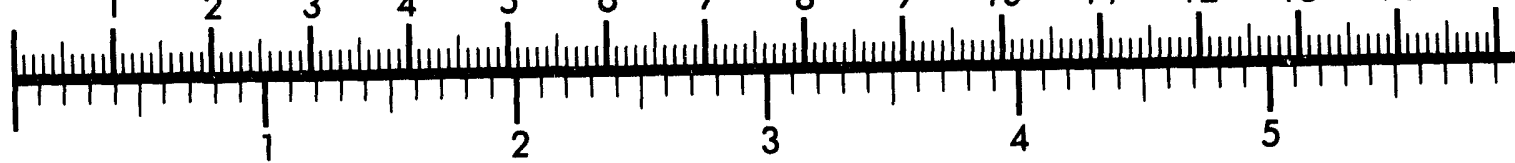
Inches
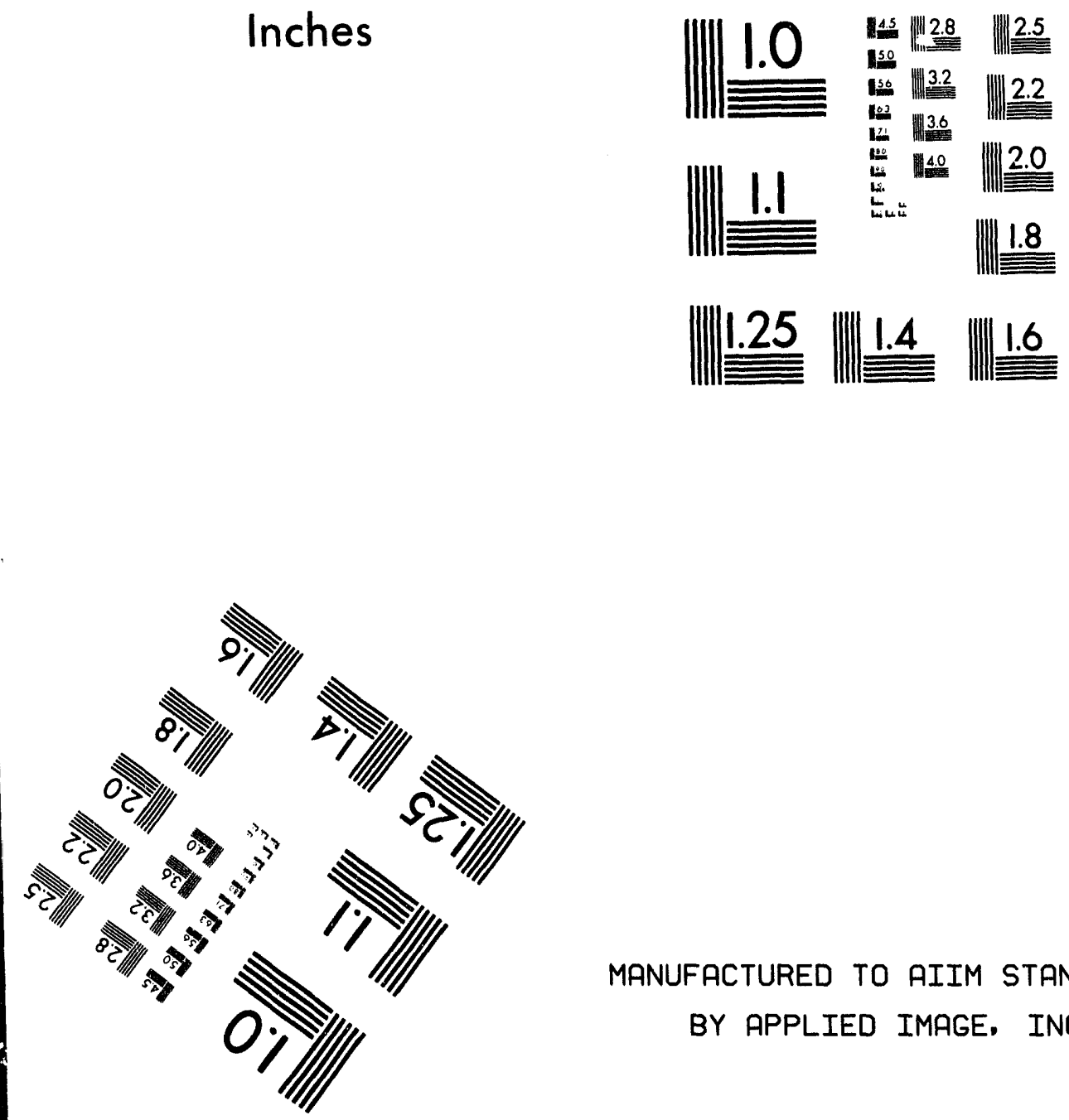

MANUFACTURED TO AIIM STANDARDS

BY APPLIED IMAGE, INC.

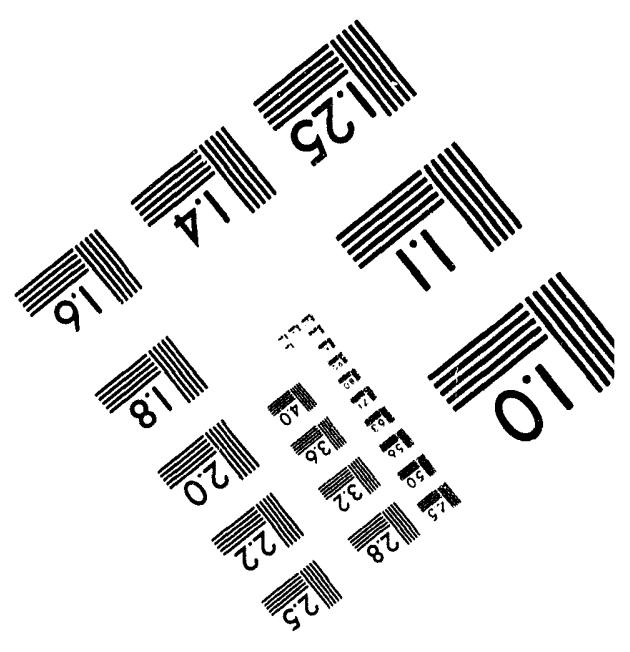



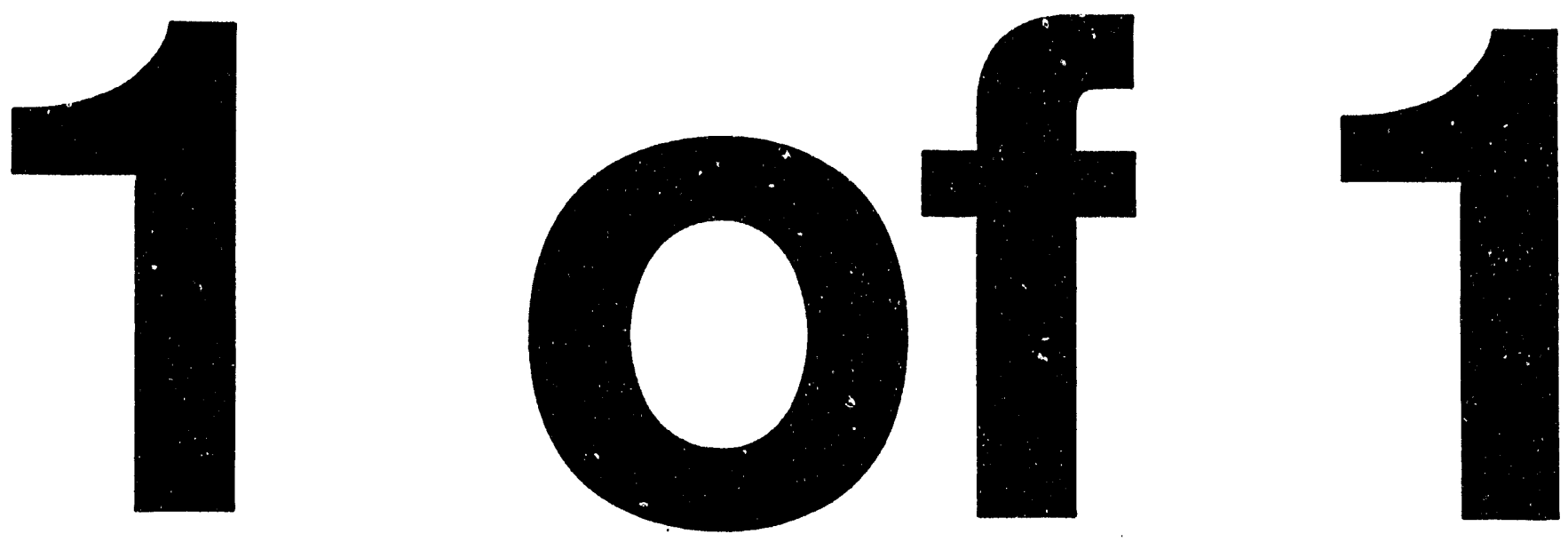

Ш 
NUREG/CR-5861

ORNL/Sub/79-7778/9

\section{Crack-Speed Relations Inferred from Large Single-Edge Notched Specimens of a 533 B Steel}

Manuscript Completed: January 1994

Date Published: July 1994

Prepared by

C. W. Schwartz

University of Maryland

Dept. of Civil Engineering

College Park, MD 20742

Oak Ridge National Laboratory

Operated by Martin Marietta Energy Systems, Inc.

Oak Ridge National Laboratory

Oak Ridge, TN 37831-6285

\section{DISCLAIMER}

This report was prepared as an account of work sponsored by an agency of the United States Government. Neither the United States Government nor any agency thereof, nor any of their employees, makes any warranty, express or implied, or assumes any legal liability or responsibility for the accuracy, completeness, or usefulness of any information, apparatus, product, or process disclosed, or represents that its use would not infringe privately owned rights. Reference herein to any specific commercial product, process, or service by trade name, trademark, manufacturer, or otherwise does not necessarily constitute or imply its endorsement, recommendation, or favoring by the United States Government or any agency thereof. The views and opinions of authors expressed herein do not necessarily state or reflect those of the United States Government or any agency thereof.

\section{Prepared for \\ Division of Engineering \\ Office of Nuclear Regulatory Research \\ U.S. Nuclear Regulatory Commission \\ Washington, DC 20555-0001}

NRC FIN B0119

Under Contract No. DE-AC05-840R21400

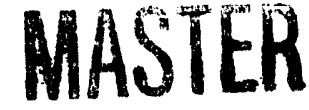




\begin{abstract}
A relationship between instantaneous crack-tip velocity $\dot{a}$, dynamic stress-intensity factor $K_{I}$, and temperature $T$ for A 533 B steel is estimated using dynamic crack position vs time data measured in a series of very largescale crack-arrest tests. The corresponding dynamic stress intensity vs time history and the dynamic-arrest toughness for each test are obtained from generation-mode elastodynamic analyses based on cubic polynomial fits to the discrete crack-position data points. Application-mode

elastodynamic analytical predictions based on the proposed $\dot{a}-K_{I}-T$ relation are within $7 \%$ of experimentally measured arrested crack lengths and within $50 \%$ of measured arrest times. These predictions represent significant improvements over results obtained using previous preliminary estimates of the $\dot{a}-\mathrm{K}_{\mathrm{I}}-\mathrm{T}$ relation for A $533 \mathrm{~B}$ steel. The influence of nonlinear material behavior on the results is also evaluated. This report is designated as HSST Report No. 141.
\end{abstract}




\section{Contents}

Page

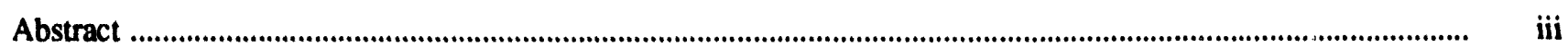

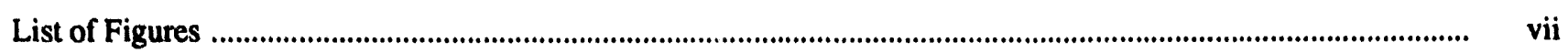

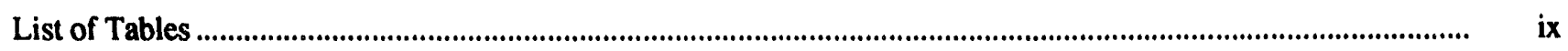

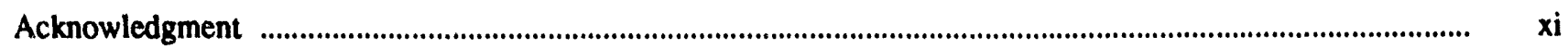

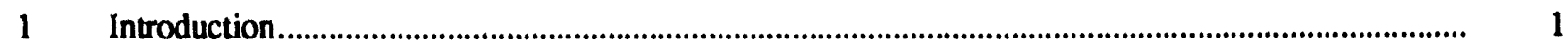

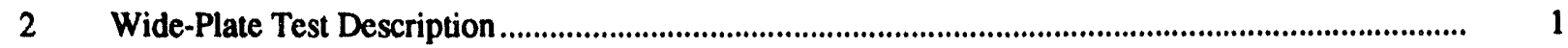

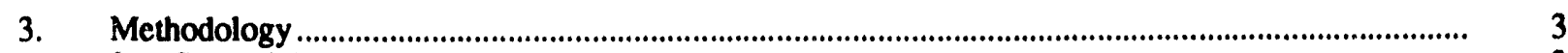

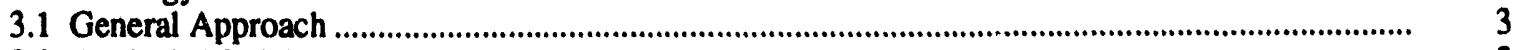

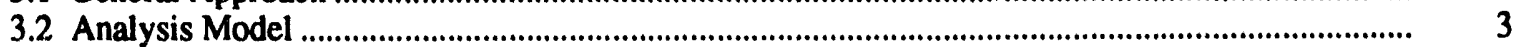

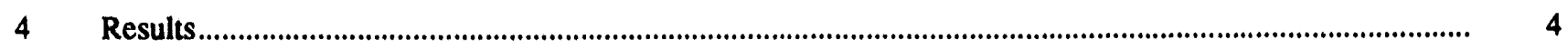

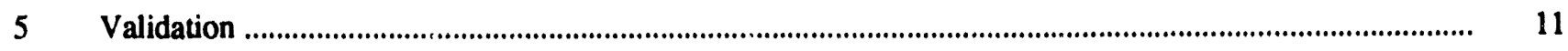

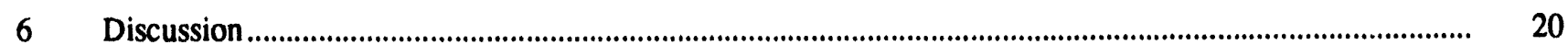

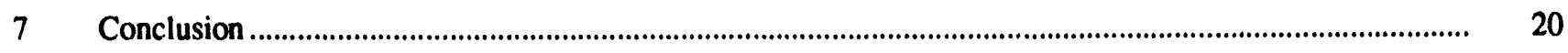

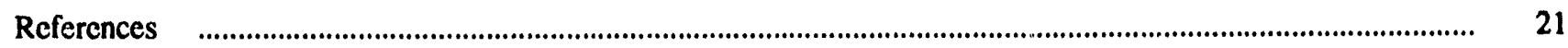




\section{List of Figures}

Figure

1 Wide-plate assembly and crack-arrest specimen: (a) pull-plate assembly and (b) specimen with strain-gage locations

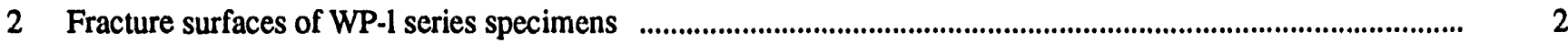

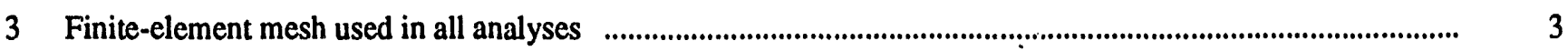

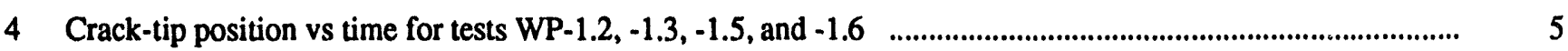

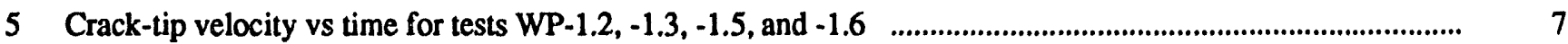

6 Generation-mode analysis predictions of dynamic stress intensity vs time for tests

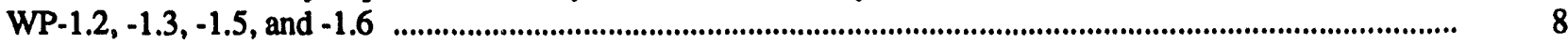

7 Arrest toughness vs temperature for A 533 B steel ........................................................................... 9

8 Dynamic stress-intensity and crack-tip velocity relationships for various temperature contours ........................ 10

9 Temperature dependence of crack-speed regression coefficients ..................................................................... 10

10 Crack-tip velocity vs dynamic stress intensity vs temperature relation inferred for A 533 B steel ..................... 11

11 Crack-tip position histories predicted from generation- and application-mode inalyses of tests WP-1.2,-1.3, -1.5, and -1.6

12 Crack-tip velocity histories predicted from generation- and application-mode analyses of tests WP-1 .2, -1 .3,-1.5, and -1.6

13 Dynamic stress-intensity histories predicted from generation- and application-mode analyses of tests WP-1 $2,-1.3,-1.5$, and -1.6

14 Crack-tip velocity histories predicted from application-mode analyses using new $\dot{\mathrm{a}}-\mathrm{K}_{\mathrm{I}}-\mathrm{T}$ relation

15 Comparison of proposed new [Eqs. (1)-(4)] and earlier estimated [Eqs. (5)-(7)] à- $\mathrm{K}_{\mathrm{I}}-\mathrm{T}$ relations for A 533 B steel

16 Crack-tip position and velocity vs time for test WP-1.7

17 Generation-mode analysis prediction of dynamic stress intensity vs time for test WP-1.7

18 Crack-tip position and velocity histories predicted from generation- and application-mode analyses of test WP-1.7

19 Dynamic stress-intensity histories predicted from generation- and application-mode analyses of test WP-1.7 


\section{List of Tables}

1 Load magnitudes and temperature profiles for all analyses

4

2 Regression results for crack position vs time for base tests WP-1.2, $-1.3,-1.5$, and -1.6

3 Application-mode analysis predictions based upon new proposed a- $\mathrm{K}_{\mathrm{I}}-\mathrm{T}$ relation for base tests WP-1.2, -1.3, -1.5, and -1.6

4 Comparison of application-mode analysis predictions using old and ncw $\mathrm{a}-\mathrm{K}_{\mathrm{I}}-\mathrm{T}$ relations

5 Application-mode analysis predictions for test WP-1.7 


\section{Acknowledgment}

Computational resources for the rescarch described in this report were provided in part by the San Diego

Supercomputer Center, which is administered and operated by GA Technologies Inc., with major funding from the National Science Foundation. 


\section{Introduction}

Assessment of the fracture integrity of nuclear reactor vessels requires an understanding of the conditions that initiate growth of existing flaws and cause arrest of moving cracks. Most prior studies of crack arrest have utilized small specimens that permit generation of data only at fracture toughness and/or temperature values below those at which arrest is postulated to occur in some pressurized-thermal-shock scenarios. The Heavy-Section Steel Technology (HSST) program at Oak Ridge National Laboratory (ORNL) has addressed this problem by collecting crack-arrest data over expanded toughness and temperature ranges through tests of several types of large specimens. ${ }^{1-4}$ In particular, tests of wide-plate specimens ${ }^{3,4}$ have generated a substantial number of data points on the arrest toughness of A 533 B steel at temperatures at or above the onset of the Charpy upper shelf.

Accurate prediction of fracture propagation and arrest for many problems requires a relationship between the instantaneous crack-tip velocity à, dynamic stress-intensity factor $\mathrm{K}_{\mathrm{I}}$, and temperature $\mathrm{T}$ for the fracturing material. This relationship, which is often unknown or poorly defined for many materials, is a primary input for predictive or "application-mode" dynamic fracture finite-element codes. 5 While the wide-plate tests are focused primarily on generating crack arrest data, they also provide information on the entire dynamic fracture process, which can be used to estimate an à- $\mathrm{K}_{\mathrm{I}}-\mathrm{T}$ relation for $\mathrm{A} 533 \mathrm{~B}$ steel.

\section{Wide-Plate Test Description}

The HSST wide-plate crack-arrest test program is designed to generate fracture data in the high-lemperature Charpy upper shelf region. A very large specimen geometry is employed to enhance constraint in the crack-tip region and to reduce dynamic effects. The first series of tests, designated WP-1, consisted of an initial set of six $0.1-\mathrm{m}$-thick specimens of A 533 B steel; these tests are the primary focus of the study reported here. Additional tests in the WP-1 series included two 0.15-m-thick specimens of the same material, and two 0.1-m-thick specimens of A 533 grade B class 1 steel having a different heat treatment. All wideplate tests were conducted at the National Institute of Standards and Technology (NIST, formerly the National Bureau of Standards) using their 27-MN loading frame. A complete description of the 0.1 -m-thick wide-plate test series is given in Ref. 3.

As shown in Fig. 1, the test specimen is a single-edgenotched (SEN) configuration. The A 533 B test material occupied the central $1 \times 1 \times 0.1 \mathrm{~m}$ thick portion of the specimen. Pull plates and tabs were welded to the A 533 B test panel to produce a specimen having an overall length of $\sim 10 \mathrm{~m}$. A starter crack located at the base of a notch extending $0.2 \mathrm{~m}$ into the specimen was created through hydrogen charging of an electron beam weld. In most of the tests, this notch was chevroned to promote crack initiation at lov load levels. Both surfaces of the specimen were side grooved to a depth of $12.5 \%$ of the plate thickness in all tests.

A rising toughness field for crack arrest was achieved by applying a temperature gradient across the width of the
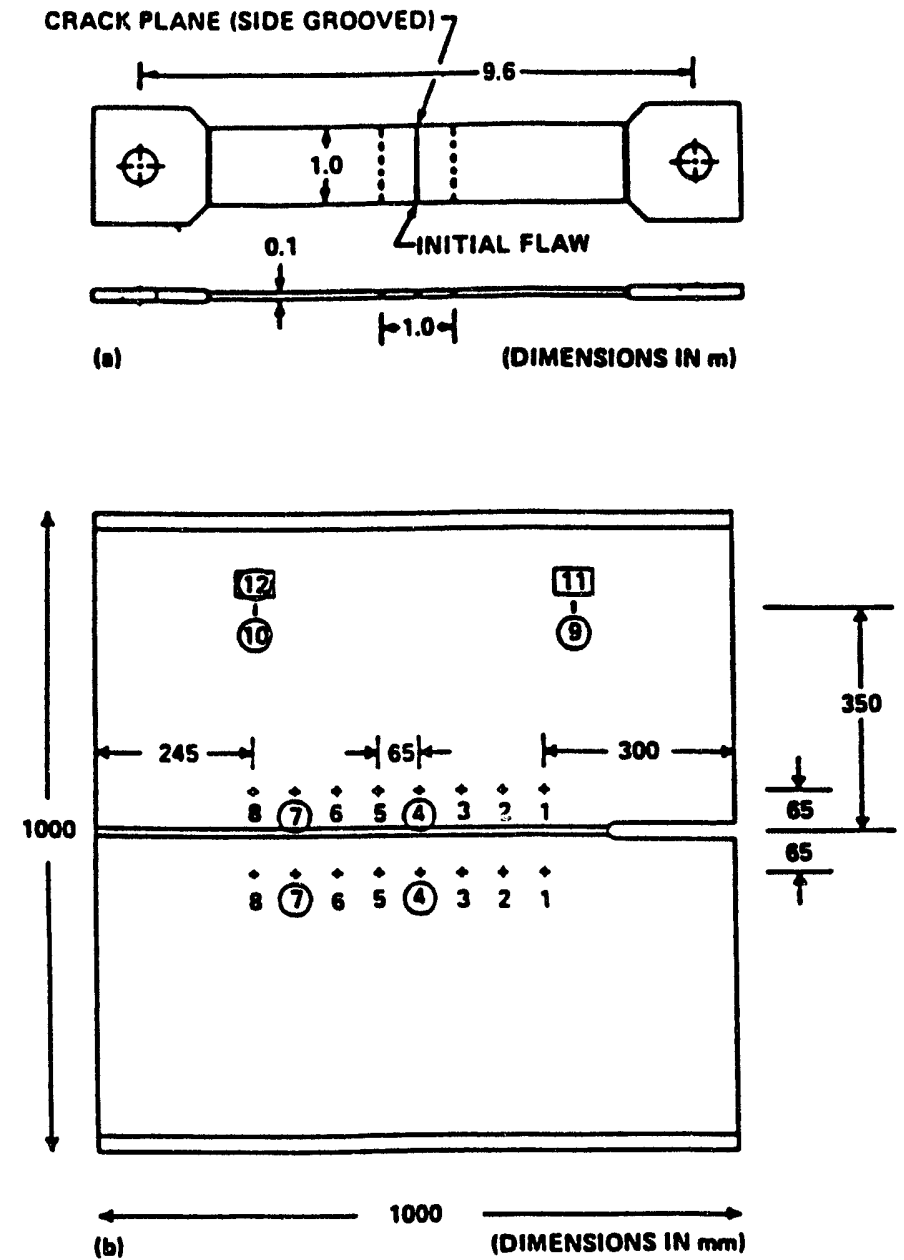

Figure 1 Wide-plate assembly and crack-arrest specimen: (a) pull-plate assembly and $(b)$ specimen with strain-gage locations 


\section{Wide-Plate}

plate. The specimens were cooled with liquid nitrogen on the notched edge and heated with electric resistance elements on the opposite edge to produce a linear temperature variation. The remote tensile load was applied through loading pins in the pull tabs at the specimen ends. Details of the test material properties, specimen configuration, temperature distributions, and load magnitudes for all tests are summarized in Ref. 3.

As shown in Fig. 1, the primary static instrumentation in the test consisted of thermocouples to monitor the temperature gradient and remote strain gauges to record applied load lcvels and out-of-plane bending. Primary dynamic instrumentation consisted of strain gauges located on the front and back sides of the specimen near the crack plane to record crack position vs time. Previous analyses ${ }^{6}$ have shown that a sharply defined strain peak is associated with a fast-running crack passing bencath the gauge location.

The WP-1 tests all exhibited crack initiation at low temperatures followed by relatively long $(0.2$ to $0.3 \mathrm{~m})$ cleav- age propagation arresting in the high-tempcrature region of the specimen. Initial arrest typically occurred within the first millisccond of response. Clcavage reinitiation and subsequent arrest, followed by ductile tearing, took place in most of the WP-1 tests. Reinitiation usually occurred after a pause of several milliseconds, during which time significant yiclding developed in the crack-tip region. Fracture surfaces for the specimens WP-1.1 through -1.6 are shown in Fig. 2. Test WP-1.1 was the only specimen that fractured significantly out-of-plane; tests WP-1.2 and -1.4 were the only specimens exhibiting appreciable tunneling at the first arrest.

Of the six 0.1-m-thick WP-1 tests, test WP-1.1 suffered an instrumentation malfunction, and the interpretation of WP-1.4 is complicated by an auxiliary pillow jack inserted in the notch to promote fracture initiation. Consequently, only data from the initial run/arrest events in the four remaining $0.1-\mathrm{m}$-thick tests (WP-1.2, $-1.3,-1.5$, and -1.6) have been used in this study.

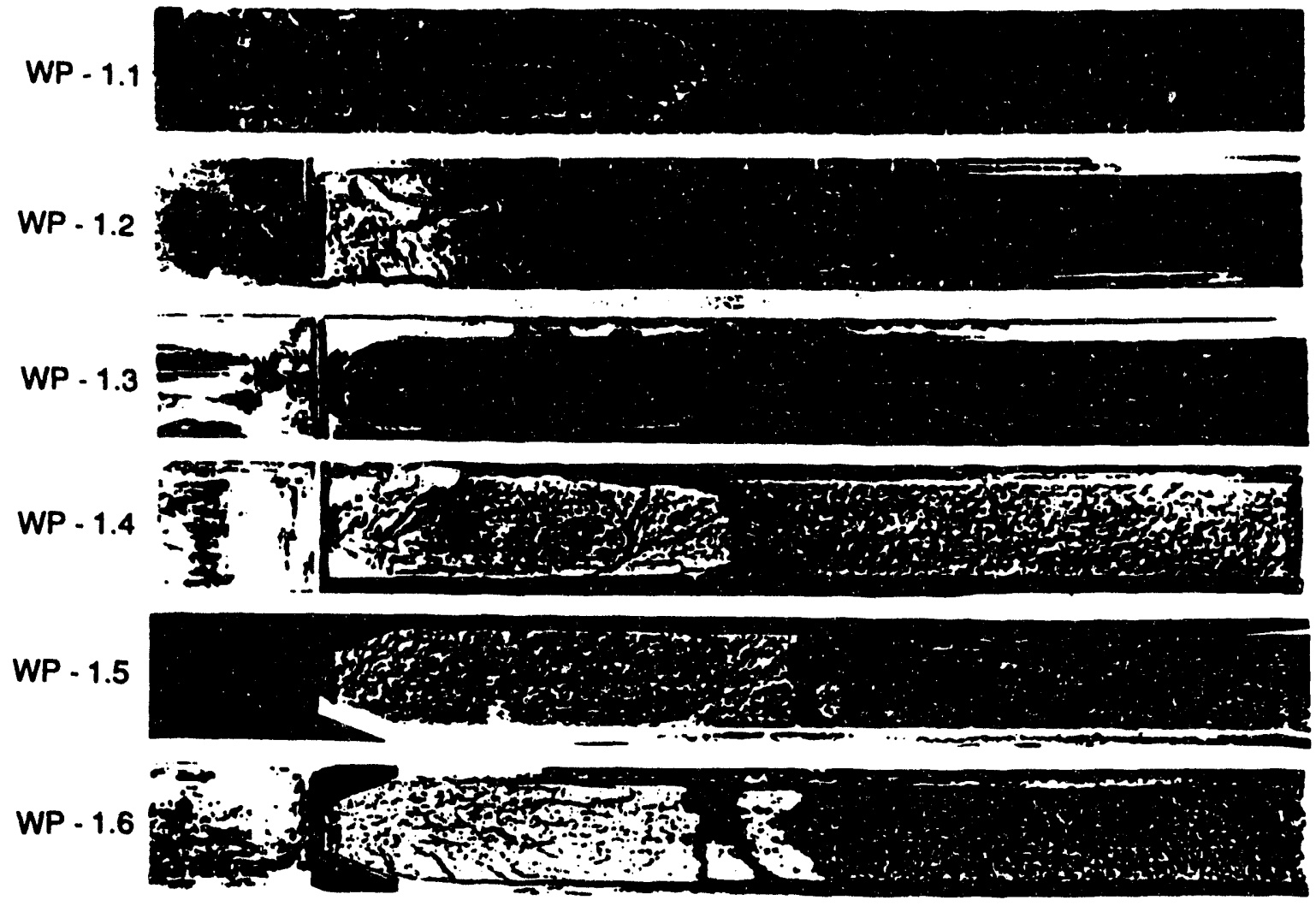

ONE METER

Figure 2 Fracture surfaces of WP-I series specimens 


\section{Methodology}

\subsection{General Approach}

The general approach employed in this study is based upon posttest "generation-mode" elastodynamic fracture analyses that take as input the crack-tip position vs time history measured experimentally in each test. The generationmode analyses compute the corresponding dynamic stress intensity vs time response, which can be correlated to the measured crack-tip position and velocity histories.

The methodology followed in estimating the $\dot{\mathrm{a}}-\mathrm{K}_{\mathrm{I}}-\mathrm{T}$ relation from the wide-plate test results is summarized as follows:

1. Smooth crack-tip position vs time curves are fit (through nonlinear regression techniques) to the discrete crack position vs time data points measured in the tests.

2. Generation-mode elastodynamic finite-element fracture analyses are performed to determine the $\mathrm{K}_{\mathrm{I}}$ vs time history and the dynamic arrest toughness $\mathrm{K}_{\mathrm{IA}}$ for each test based on the crack-tip position vs time polynomial fit.

3. The $\mathrm{K}_{\mathrm{IA}}$ values computed in the WP-1 generation. mode analyses, together with other large-scale crac'sarrest data, are used to devclop a revised relationship between arrest toughness and temperature.

4. Commensurate with the limited data available from the four WP-1 tests, a simple linear form is assumed for the $\dot{\mathrm{a}}-\mathrm{K}_{\mathrm{I}}-\mathrm{T}$ relation for the material:

$$
\begin{aligned}
& \dot{a}=c_{0}+c_{1} \times\left(K_{I} / K_{I A}\right) \quad K_{I} / K_{I A} \geq 1 \\
& \dot{a}=0 \quad K_{I} / K_{I A}<1
\end{aligned}
$$

in which the coefficients $c_{0}$ and $c_{l}$ are functions of tcm. perature. [Note that the KIA relation determined in Step 3 is used to normalize the second term in Eq. (1).] A two-stage regression analysis is performed to determine $c_{0}$ and $c_{1}$ :

(a) Crack-tip velocity vs $\mathrm{K}_{\mathrm{I}}$ data points are extracted from the generation-mode analysis results at various selected temperatures. Data at constant temperature values are $f_{i i}$ with linear relations of the form of Eq. (l); a different pair of $\mathrm{c}_{0}$ and $\mathrm{c}_{1}$ coefficients are determined for each temperature valuc.

(b) The sets of coefficients determined in Step 4(a) are regressed against temperature.

Note that the a vs $\mathrm{K}_{\mathrm{I}}$ relation could theoretically be derived from a single test if there were no temperature dependence of the fracture propertics. Inclusion of tcmpcrature effects requires data from several tests.

\subsection{Analysis Model}

All dynamic-fracture analyses in this study were performed using the SAMCR elastodynamic finite-element code. 5

Static displacements at initiation were computed using the ADINA general-purpose, finite-element code ${ }^{7}$ and input as initial conditions to SAMCR. The finite-element mesh, illustrated in Fig. 3, consisted of 1274 nodes and 11904 noded quadrilateral isoparametric plane stress elements. All elements along the crack plane were square with a side length equal to 0.05 times the specimen width. The maximum aspect ratio for any element was limited to 5 to minimize spurious internal wave reflections during the dynamic calculations. Although there were slight variations in the specimen geometry from one test to the next, these were neglected in the analyses, and the same finite-element mesh was used throughout.

The load values and temperature distributions for the four 0.1 -m-thick specimens analyzed are summarized in Table 1. (Also included in the table are data for the $0.15-\mathrm{m}$-thick

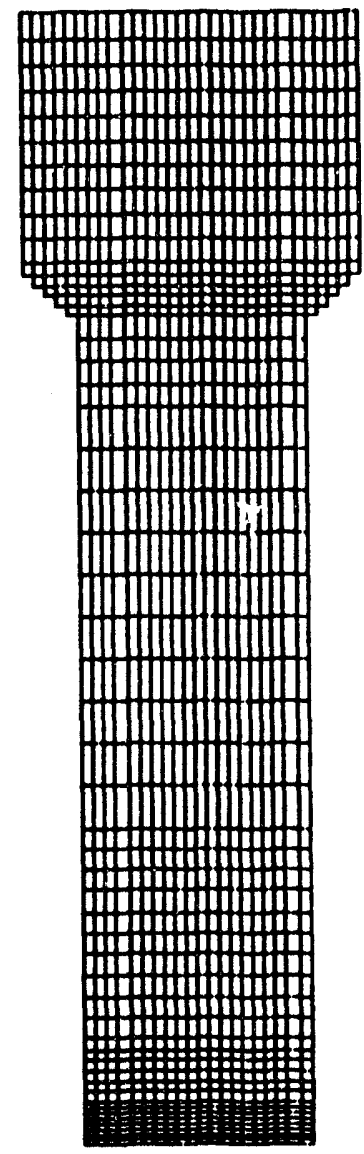

Figure 3 Finite-element mesh used in all analyses 
Table 1 Load magnitudes and temperature profiles for all analyses

\begin{tabular}{llllll}
\hline & \multicolumn{5}{c}{ Test } \\
\cline { 2 - 6 } & WP-1.2 & WP-1.3 & WP-1.5 & WP-1.6 & WP-1.7 \\
\hline $\begin{array}{l}\text { Load, MN } \\
\text { Temperature, }{ }^{\circ} \mathrm{C}\end{array}$ & 18.90 & 11.25 & 11.03 & 14.50 & 26.20 \\
$\begin{array}{l}\text { Cold edge } \\
\text { Hot edge }\end{array}$ & -97 & -120 & -84 & -70 & -70 \\
\hline
\end{tabular}

spccimen WP-1.7; this test will be discussed later.) The temperature distributions are defined in terms of the coldand hot-edge temperatures, assuming an ideal linear distribution across the specimen. The temperature gradients induced significant thermal bowing in the specimens at initiation. This thermal bowing is incorporated in the analyses in an approximate fashion by giving the applied load a slight eccentricity from the centerline. The ADINA finite-element code was used to compute the pure thermal displacements, assuming that the linear temperature gradient across the specimen was constant over the central 2-m length and attenuated linearly to uniform ambient conditions at the pull tabs. The calculated lateral thermal displacement of the centerline of the specimen at the crack plane was taken as the load eccentricity. This approximate incorporation of the thermal bowing effect resulted in a 6 to $10 \%$ increase in the $K_{I}$ values computed at initiation.

No attempt was made to model the details of the loading pin in the analyses. The load was simply applied as a pair (to permit the thermal bowing load eccentricity) of concentrated nodal loads at the location of the load pin. The static displacement fields induced by these loads were used as the initial conditions for the dynamic-fracture calculations. A fixed-displacement condition was enforced at the load points throughout the dynamic calculations.
The A 533 B test specimen material, pull plates, and pull tabs were all modeled as isotropic linearly elastic matcrials having the following properties:

$\begin{array}{ll}\text { Young's modulus } & 206.8 \mathrm{GPa} \\ \text { Poisson's ratio } & 0.3 \\ \text { Mass density } & 7850.0 \mathrm{~kg} / \mathrm{m}^{3} \\ \text { Coefficient of thermal } & 11.0 \mathrm{E}-6 \mathrm{~m} / \mathrm{m}-{ }^{\circ} \mathrm{C} \\ \quad \text { expansion } & \end{array}$

Details of the analysis algorithms incorporated in SAMCR are given in Ref. 5. Crack advance is modeled using a crack-tip nodal release force technique. A linear release force vs crack-tip position relationship was used in all analyses. The dynamic stress-intensity factor $\mathrm{K}_{\mathrm{I}}$ is derived from a "moving contour" J-integral calculation; ( $N N N=1$, $\mathrm{NT}=2, \mathrm{NL}=3$ in SAMCR); the effect of side grooving is included in converting $J$ to $K$. Spatial integrations of the element stiffness, mass, and damping matrices are performed using one-point Gauss quadrature with a stiffness correction scheme to eliminate "keystone" deformation modes. Time integrations are based upon an explicit central-difference scheme; time step sizes were $-0.75 \mu \mathrm{s}$ in all analyses (RDT $=0.2$ in SAMCR). Artificial bulk viscosity was employed to increase the stability of the calculations over time (B1 $=0.12, \mathrm{~B} 2=0.06, \mathrm{~B} 3=0.01$ in SAMCR). No smoothing of the calculated values over time was performed in any of the analyses.

\section{Results}

The strain gauges located near the crack plane provide data on the position of the crack front at discrete points in time. Typically, 6 to 12 crack-position data points were recorded during the first run-arrest event in each test. Smooth cracktip position vs time curves are fitted to the measured crack history data points using nonlinear polynomial regression techniques. Figure 4 summarizes the crack position vs time data obtained from the crack-line strain gauges for the four 0.1-m-thick specimens considered in this study, along with .te computed regression curves for the crack position histories. As summarized in Table 2, cubic polynomials were found to provide an excellent fit to the data, with $R^{2}$ values exceeding 0.98 in all cases.

Determination of the initiation time from the instrumentation records often involved considerable subjective 
u
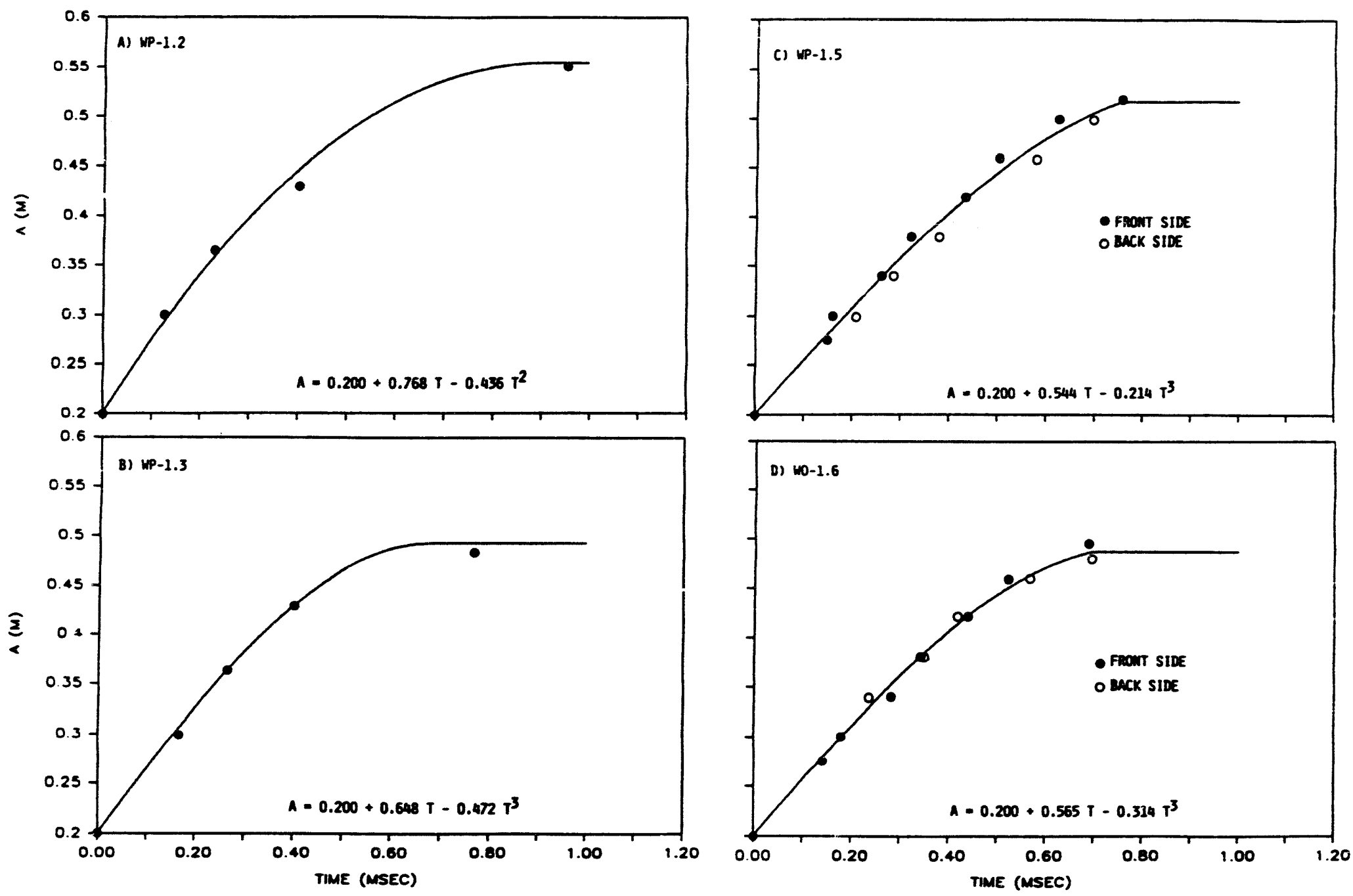

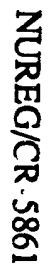

Figure 4 Crack-tip position vs time for tests WP-1.2, -1.3, -1.5, and -1.6 
Results

Table 2 Regression results for crack position vs time for base tests WP-1.2, -1.3,-1.5, and -1.6

\begin{tabular}{ccccccc}
\hline & \multicolumn{6}{c}{$\mathbf{a}=\mathbf{d}_{\mathbf{0}}+\mathbf{d}_{\mathbf{1}} * \mathbf{t}+\mathbf{d}_{2} * \mathbf{t}^{2}+\mathbf{d}_{\mathbf{3}} \boldsymbol{t}^{\mathbf{3}}$} \\
\cline { 2 - 7 } Test & $\mathbf{d}_{\mathbf{0}}$ & $\mathbf{d}_{\mathbf{1}}$ & $\mathbf{d}^{\mathbf{2}}$ & $\mathbf{d}_{\mathbf{3}}$ & $\mathbf{R}^{2}$ & $\begin{array}{c}\text { Time } \\
\text { shift (ms) }\end{array}$ \\
\hline WP-1.2 & 200.0 & 786.5 & -435.9 & $a$ & 0.9975 & $\mathrm{NA}^{b}$ \\
WP-1.3 & 200.0 & 648.0 & $a$ & -471.5 & 0.9998 & $\mathrm{NA}^{b}$ \\
WP-1.5 & 200.0 & 543.6 & $a$ & -214.3 & 0.9975 & 32 \\
WP-1.6 & 200.0 & 564.7 & $a$ & -313.9 & 0.9993 & 70 \\
\hline
\end{tabular}

${ }^{a}$ Coefficient does not add significantly to regression fit.

$b_{\mathrm{NA}}=$ not applicable.

interpretation, as the triggering system did not provide an absolute time zero for the dynamic strain gauge records. Tests WP-1.5 and -1.6 contained enough data points to permit a more refined estimate of the initiation time, however. For these tests, a polynomial curve is first fit to the raw strain gauge data points without constraining the curve to pass through the known initial crack-tip location, at the assumed time zero. This curve is then extrapolated to the initial crack-tip location, and the corresponding time is computed. This extrapolated time value is taken as the corrected initiation time, and all strain gauge data points are adjusted accordingly. Last, a revised polynomial curve constrained to pass through the corrected initiation time is fit to the adjusted crack position vs time data. The initiation time corrections equalled 32 and $70 \mu$ s for tests WP-1.5 and -1.6 , respectively. The data shown in Fig. $4(c)$ and $(d)$ include these initiation time corrections. The initiation time correction procedure was not applied to tests WP-1.2 and -1.3 because of the very small number of experimental data points.

The polynomial relations for crack-position history are primary inputs to the generation-mode dynamic fracture analyses. Crack-tip velocities vs time computed in the generation mode analyses are presented in Fig. 5. Also shown in these figures are the crack-tip velocities computed from the measured crack-tip position data assuming constant velocity between each position data point. By design, the velocities calculated from the generation-mode analyses provide a much smoother representation of the crack-tip velocity history. In particular, sharp transient peaks in the "measured" velocity data (such as in test WP-1.5 at $150 \mu \mathrm{s}$ ) are eliminated in the computed velocity histories. It is unlikely that these sharp transient peaks actually occurred in the test; more probably, they are simply the consequence of noise/measurement uncertainty in the discrete crack-tip position data from which the "measured" velocity values are obtained.

The dynamic stress-intensity vs time records computed in the generation-mode analyses are plotted in Fig. 6. Also shown on the figure are the values of computed $\mathrm{K}_{\mathrm{I}}$ at arrest. As expected for the wide-plate test configuration, arrest occurs in a rising $\mathrm{K}_{I}$ field. $\mathrm{K}_{\mathrm{I}}$ continues to increase with time after the initial arrest, indicating that a significant elevation of $\mathrm{K}_{\mathrm{I}}$ above the arrest value is required for reinitiation.

Table 3 summarizes the generation-mode analysis results at arrest, including the computed dynamic arrest toughness $\mathrm{K}_{\mathrm{IA}}$. The crack-tip temperature at arrest is based upon the actual temperature profile across the specimen as measured by the thermocouples near the crack plane.

Figure 7 shows the relationship between $\mathrm{K}_{\mathrm{IA}}$ and temperature, normalized as T - RT NDT, computed for the WP-1 tests (RTNDT for the WP-1 material is $-23^{\circ} \mathrm{C}$ ). Also plotted on the figure are data from other large-scale crackarrest tests. ${ }^{1,2,8}$ The relationship between $\mathrm{K}_{\mathrm{IA}}$ and temperature determined from nonlinear regression analysis of these data is given as:

$$
\begin{aligned}
\mathrm{K}_{\mathrm{IA}}= & 69.56+5.11 \times \mathrm{e}^{\left[0.04658\left(\mathrm{~T}-\mathrm{RT}_{\mathrm{NDT}}\right)\right]} \\
& \left(\mathrm{MN}-\mathrm{m}^{3 / 2} ;{ }^{\circ} \mathrm{C}\right) .
\end{aligned}
$$

Contours of $\left(\dot{\mathrm{a}}, \mathrm{K}_{\mathrm{I}}\right)$ data pairs at constant temperature computed from the generation-mode analyses are illustrated in Fig. 8. Each test provides one data point on each 

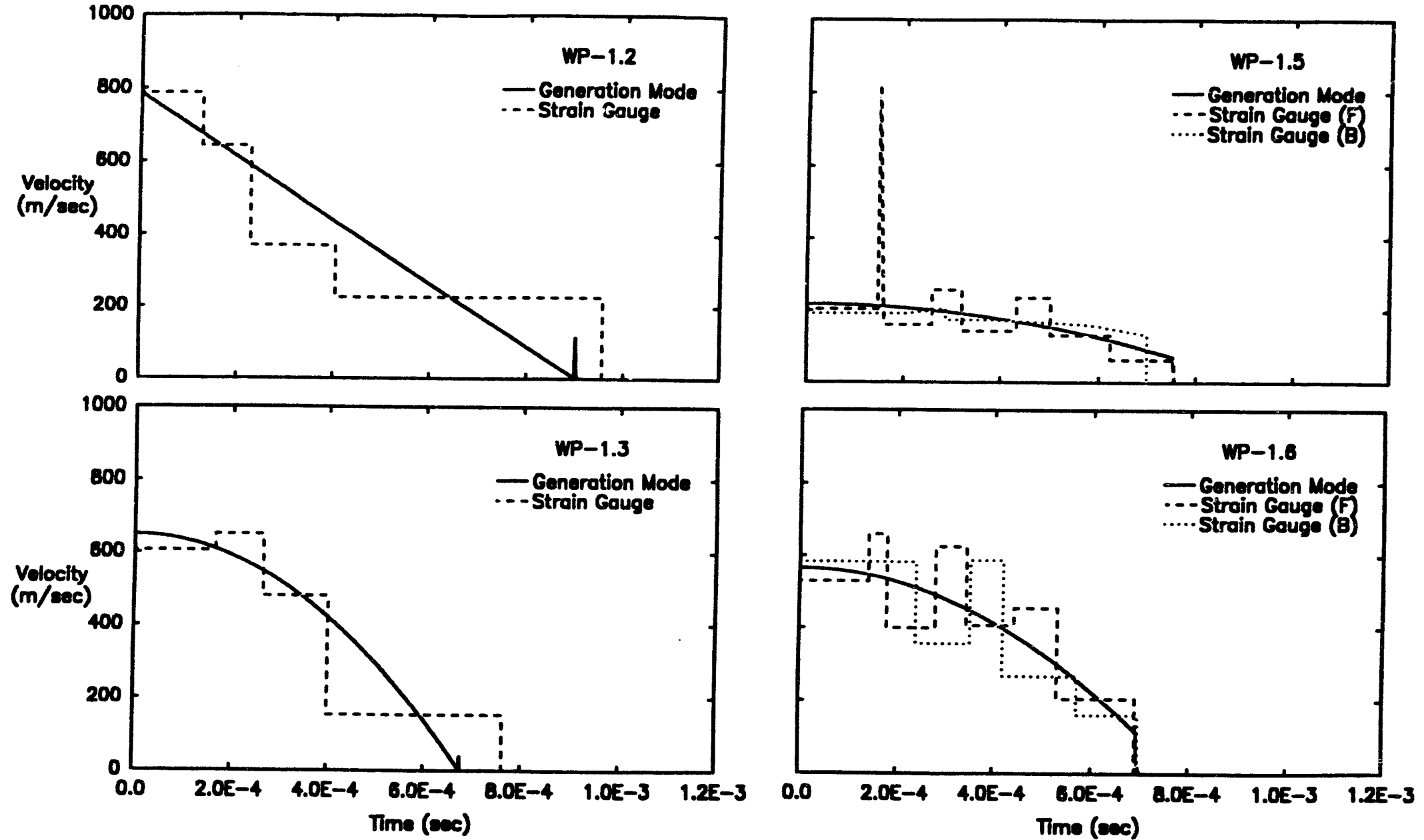

Figure 5 Crack-tip velocity vs time for tests WP-1.2, -1.3, -1.5, and -1.6 

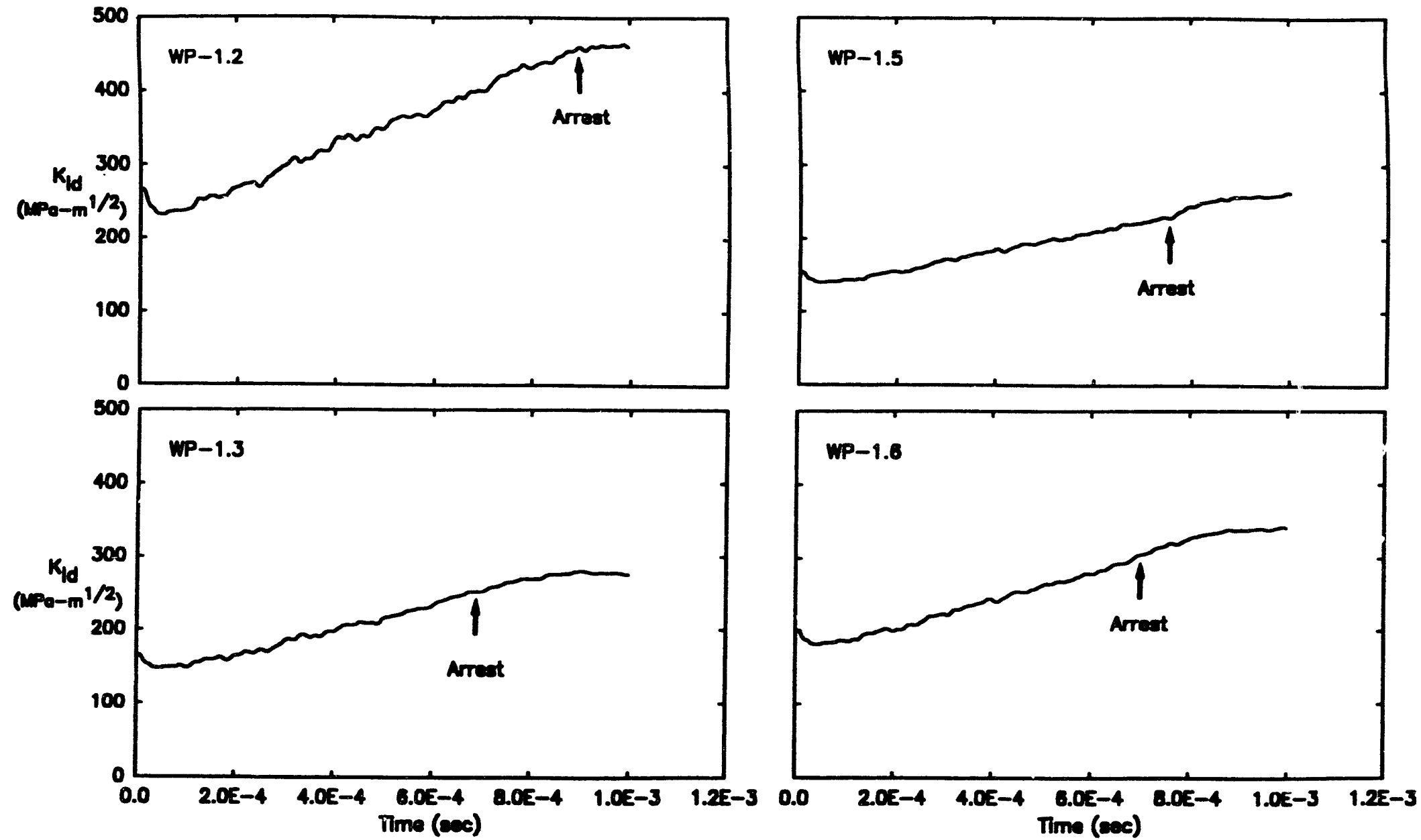

Figure 6 Generation-mode analysis predictions of dynamic stress intensity vs time for tests WP-1.2, -1.3, -1.5, and -1.6 
Results

Table 3 Application-mode analysis predictions based upon new proposed a-K $K_{I}-T$ relation for base tests WP-1.2, -1.3, -1.5, and -1.6

\begin{tabular}{|c|c|c|c|c|c|c|c|c|}
\hline & \multicolumn{2}{|c|}{ WP-1.2 } & \multicolumn{2}{|c|}{ WP-1.3 } & \multicolumn{2}{|c|}{ WP-1.5 } & \multicolumn{2}{|c|}{ WP-1.6 } \\
\hline & EXP/GEN & APP & EXP/GEN & APP & EXP/GEN & APP & EXP/GEN & APP \\
\hline Time $t_{f}, \mathrm{~ms}$ & 0.907 & $0.898-1.023$ & 0.680 & 0.598 & 0.762 & 0.668 & 0.701 & 0.946 \\
\hline $\begin{array}{l}\text { Crack length } \\
\text { af, } m\end{array}$ & 0.555 & $0.556-0.562$ & 0.493 & 0.476 & 0.518 & 0.500 & 0.487 & 0.522 \\
\hline $\begin{array}{l}\text { Toughness } \\
\mathrm{K}_{\mathrm{IA}}, \mathrm{MPa}-\mathrm{m}^{1 / 2}\end{array}$ & 457 & $464-482$ & 252 & 224 & 233 & 222 & 305 & 329 \\
\hline $\begin{array}{l}\text { Temperature } \\
\text { T - RT } \\
\text { NDT, }{ }^{\circ} \mathrm{C}\end{array}$ & 85.6 & $85.9-87.8$ & 79.5 & 73.4 & 77.7 & 73.0 & 76.9 & 85.3 \\
\hline
\end{tabular}

Notes: $\quad E X P=$ experimental results ( $t_{f}$, af,$\left.T-R T_{N D T}\right)$

GEN = generation-mode analysis results $\left(\mathrm{K}_{\mathrm{IA}}\right)$

APP = application-mode analysis results (all)

Crack-tip semperature is actual temperature as measured by crack plane thermocouples.

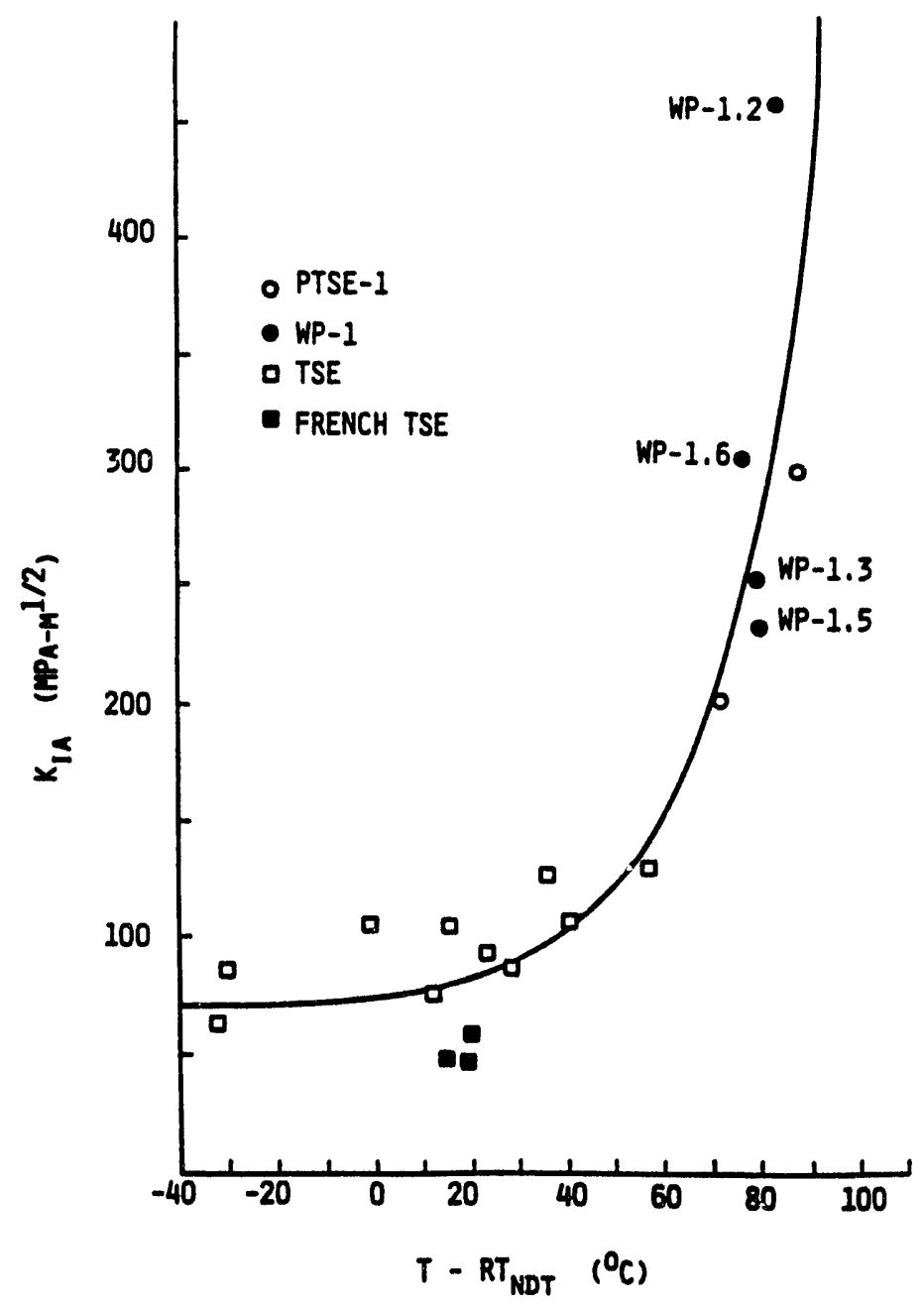

Figure 7 Arrest toughness vs temperature for A 533 B steel 
Results

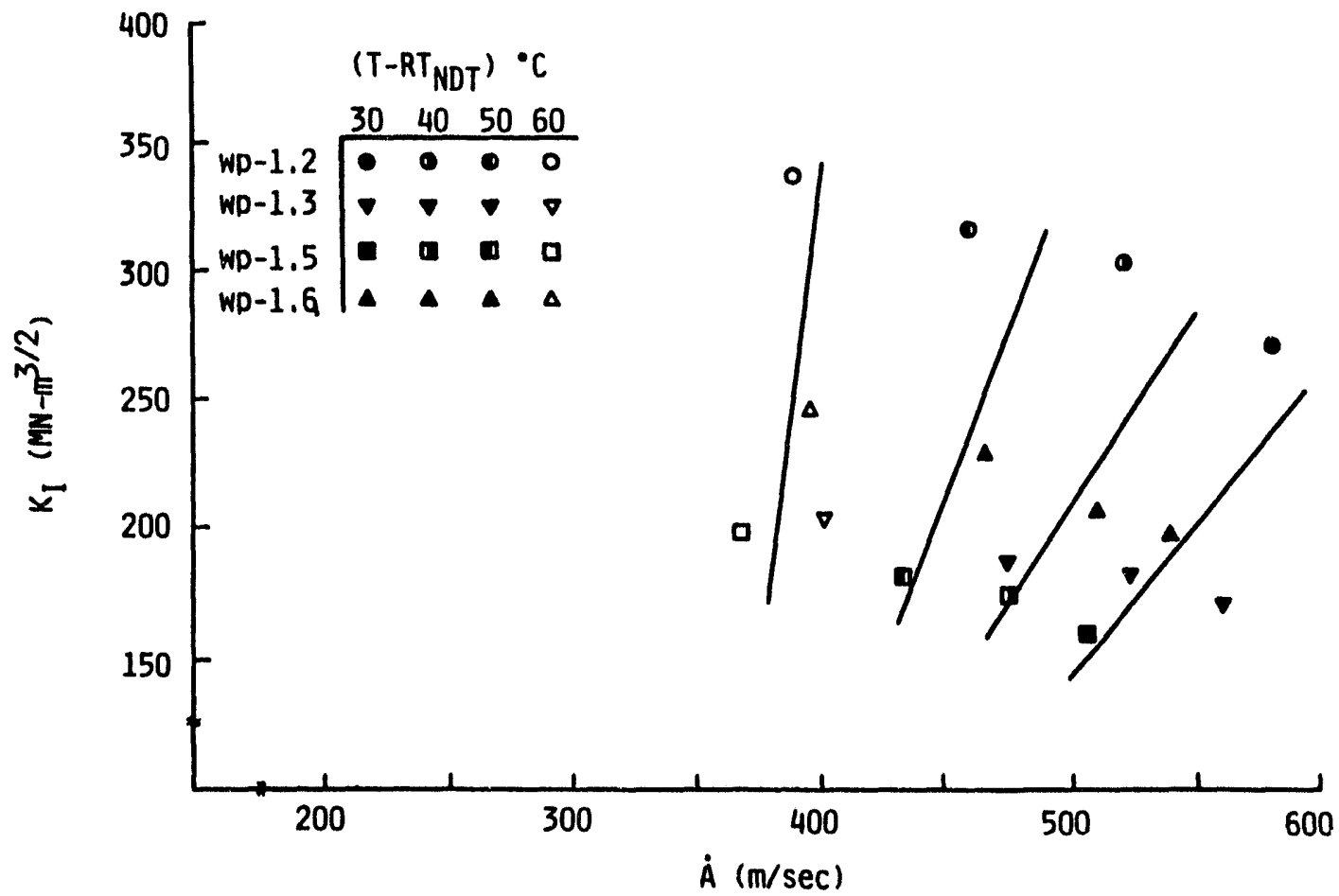

Figure 8 Dynamic stress-intensity and crack-tip velocity relationships for various temperature contours

tempcrature contour. The data at cach temperature contour are fit with lincar cquations, with cach tempcrattire contour defined by a different set of cocfficients. The variation of these cocfricients, with tempcrature shown in Fig. 9, is well represented by quadratic polynomial regressions:

$$
\begin{aligned}
c_{0}=193 & +14.1 \times\left(\mathrm{T}-\mathrm{RT}_{\mathrm{NDT}}\right) \\
& -0.183 \times\left(\mathrm{T}-\mathrm{RT}_{\mathrm{NDT}}\right)^{2}\left(\mathrm{~m} / \mathrm{s} ;{ }^{\circ} \mathrm{C}\right), \\
\mathrm{c}_{1}=168 & -5.62 \times\left(\mathrm{T}-\mathrm{RT}_{\mathrm{NDT}}\right) \\
& +0.484 \times\left(\mathrm{T}-\mathrm{RT}_{\mathrm{NDT}}\right)^{2}\left(\mathrm{~m} / \mathrm{s} ;{ }^{\circ} \mathrm{C}\right) .
\end{aligned}
$$

The final $\dot{a}-\mathrm{K}_{\mathrm{I}}-\mathrm{T}$ relation inferred for A 533 B steel from the four WP-1 tests is shown in Fig. 10. The relation is based upon the general form given in Eq. (1), with terms as defined in Eqs. (2)-(4). At constant temperature, the relation is linear with a vertical stem at $\mathrm{K}_{\mathrm{I}} / \mathrm{K}_{\mathrm{IA}}=1$. Both the slope and the velocity cutoff for the upper portion of the relation are temperature dependent. In particular, the $c_{1}$ cocfficient, which represents the slope of the upper portion of the relation, decreases with temperature until $T-R T_{N D T}$ reaches $\sim 58^{\circ} \mathrm{C}$, at which point $c_{1}$ begins to increase again. In the absence of better information, it is suggested that $c_{1}$ be set equal to zero for relative temperatures $>58^{\circ} \mathrm{C}$. Based on the underlying data, this proposed ${ }^{\circ}$ $\dot{\mathrm{a}}-\mathrm{K}_{\mathrm{I}}-\mathrm{T}$ relation is valid over a temperature range of $\sim 20$ to $70^{\circ} \mathrm{C} \mathrm{T}-\mathrm{RT}$ NDT. Confident extrapolation to substantially lower and/or higher temperatures will require additional data.
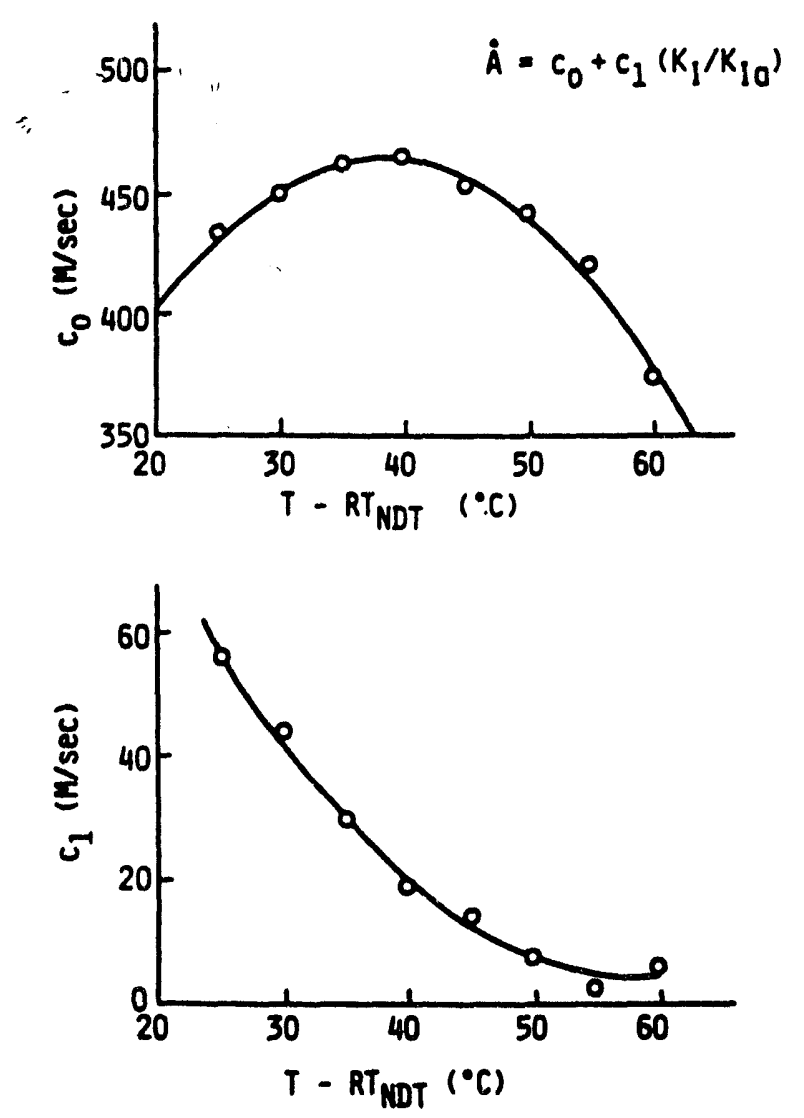

Figure 9 Temperature dependence of crack-speed regression coefficients 
Results

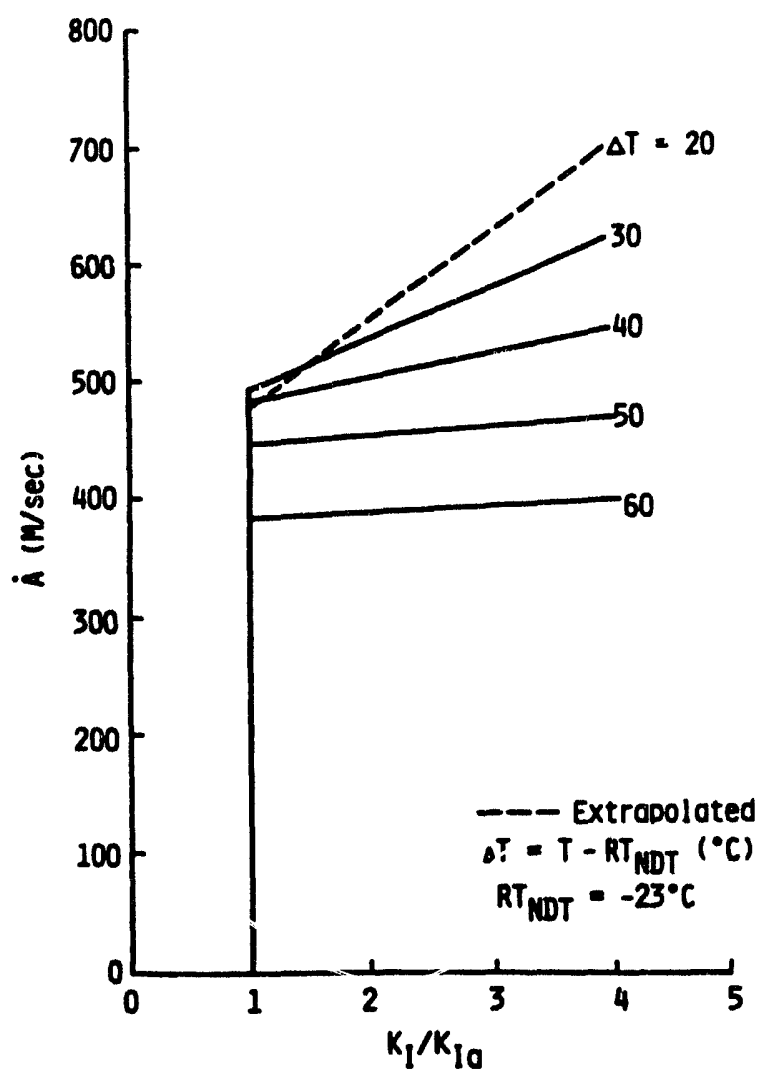

Figure 10 Crack-tip velocity vs dynamic stress intensity vs temperature relation inferred for A 533 B steel

\section{Validation}

As initial validation of the proposed $\dot{\mathrm{a}}-\mathrm{K}_{\mathrm{I}}-\mathrm{T}$ relation, application-mode elastodynamic fracture analyses were performed for tests WP-1.2, $-1.3,-1.5$, and -1.6 in which the crack tip vs time response is predicted given the proposed $\dot{a}-K_{I}-T$ relation as input. These application-mode analyses used the actual temperature distributions across the specimen as measured by the thermocouples in each test. Comparisons between these new application-mode and the previous generation-mode analysis results are shown in Figs. 11, 12, and 13 for the computed crack-tip position, velocity, and $\mathrm{K}_{\mathrm{I}}$ histories, respectively. [Note: the curves in the figures labeled "Application-Mode (Old)" will be discussed later.] The figures clearly show the very close agreement between the two sets of analysis results. The largest discrepancies occur in the computed velocitics at very small time values.

Table 3 summarizes the arrest conditions predicted in the application-mode analyses as compared to the experimental data and to the results from generation-mode com- putations. (Note that the experimentally measured arrest positions and times are by definition identical to the generation-mode analysis values.) As shown in Fig. 14, arrest is poorly defined in the application-mode analysis results for test WP-1.2 because of residual low-velocity crack advance that persists for comparatively long durations late in the event. The experimental data (and the generation-mode analysis results derived from this experimental data), in contrast, indicate a more abrupt arrest of the crack. Bccause it is unlikely that a crack will propagate for long at very low velocitics in comparatively ductile materials like A 533 B steel, arrest has been arbitrarily defined here to occur when the crack velocity drops below a threshold velocity of $\sim 1$ to $2 \%$ of shear wave velocity. (The shear wave velocity for A 533 B stcel is $3184 \mathrm{~m} / \mathrm{s}$.)

As detailed in Table 3, the application-mode analysis predictions for the time of arrest range from an underestimate of $-15 \%$ (WP-1.3 and -1.5) to an overestimate of 35\% (WP-1.6) as compared to the experimental/generation- 
Z
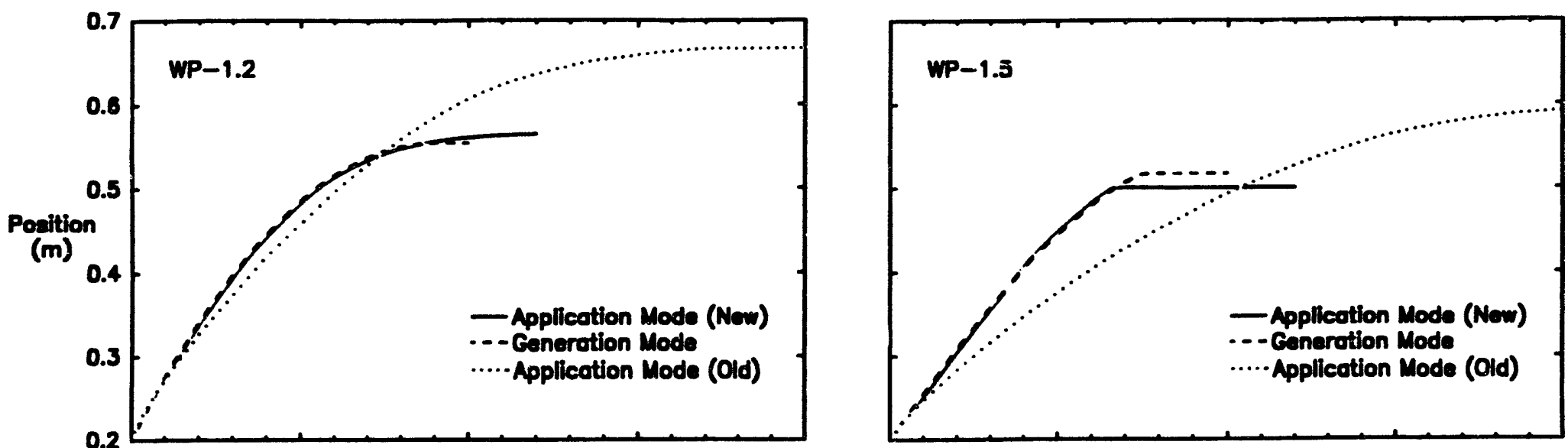

$\bar{N}$
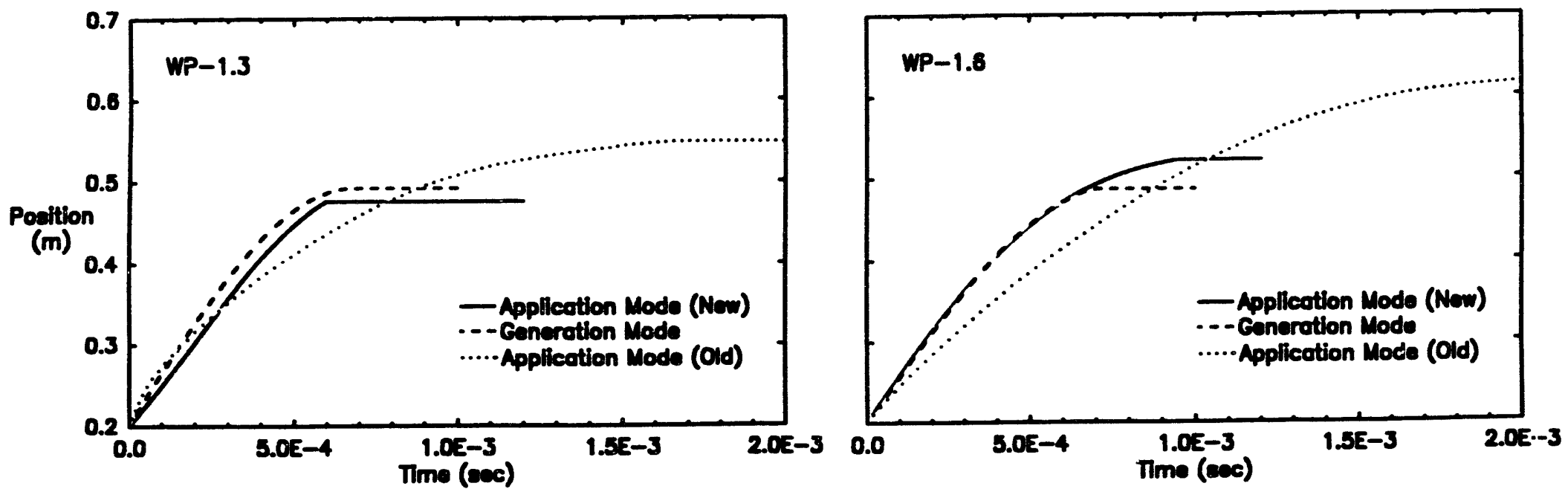

Figure 11 Crack-tip position histories predicted from generation- and application-mode analyses of tests WP-1.2, $-1.3,-1.5$, and -1.6 

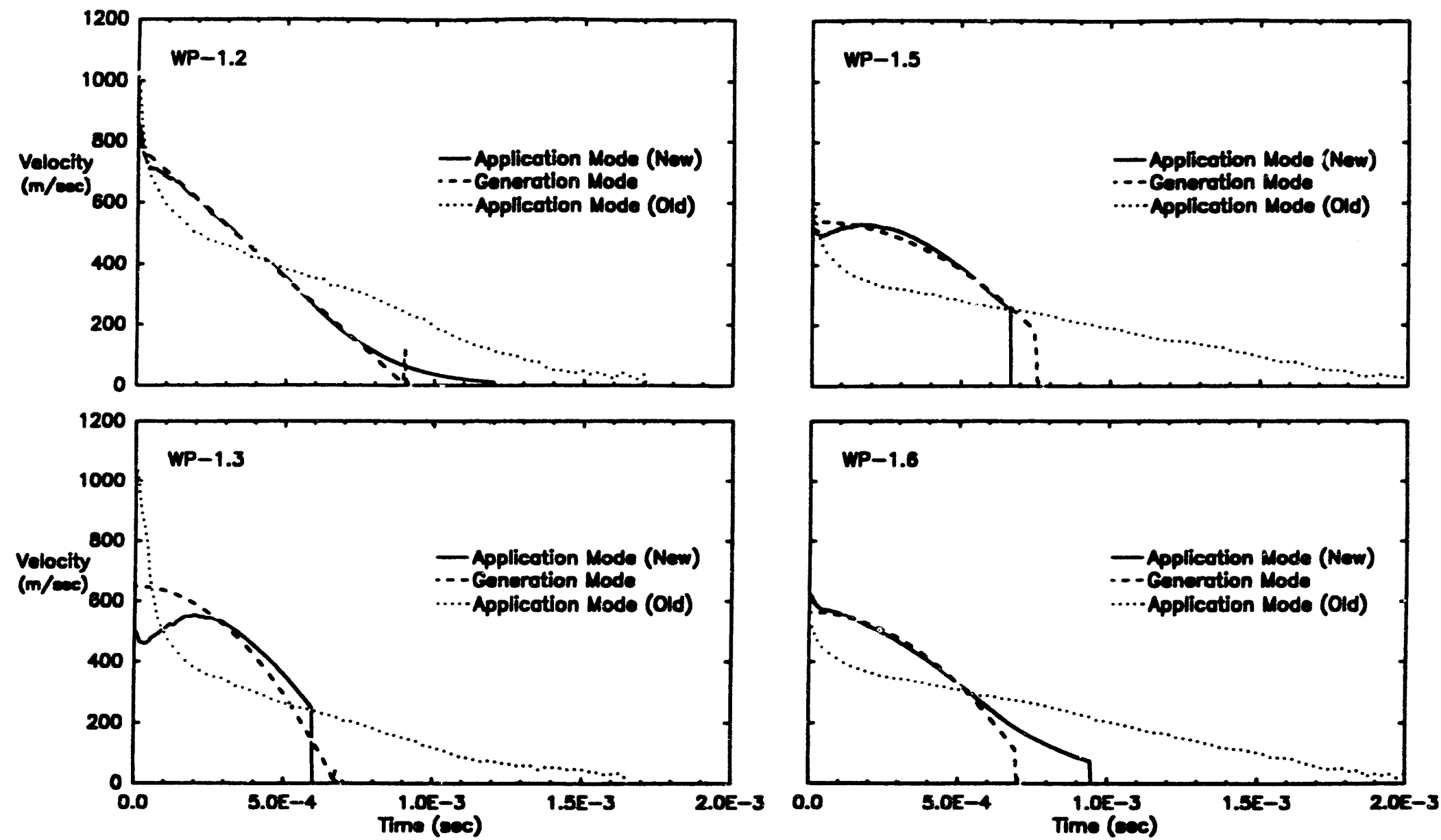

Figure 12 Crack-tip velocity histories predicted from generation- and application-mode analyses of tests WP-1.2, $-1.3,-1.5$, and -1.6 

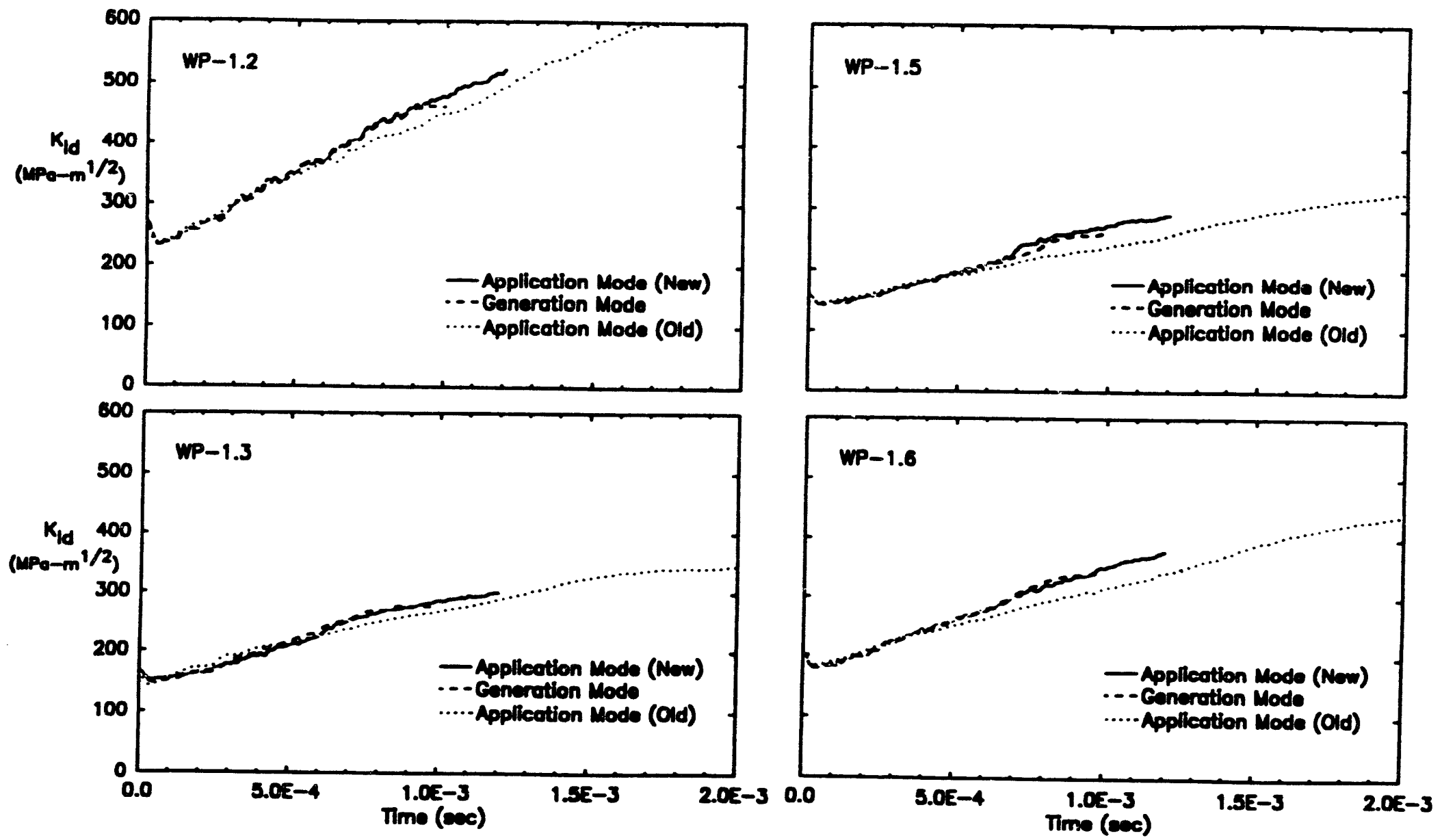

Figure 13 Dynamic stress intensity histories predicted from generation- and application-mode analyses of tests WP-1.2, -1.3, -1.5, and -1.6 
Validation

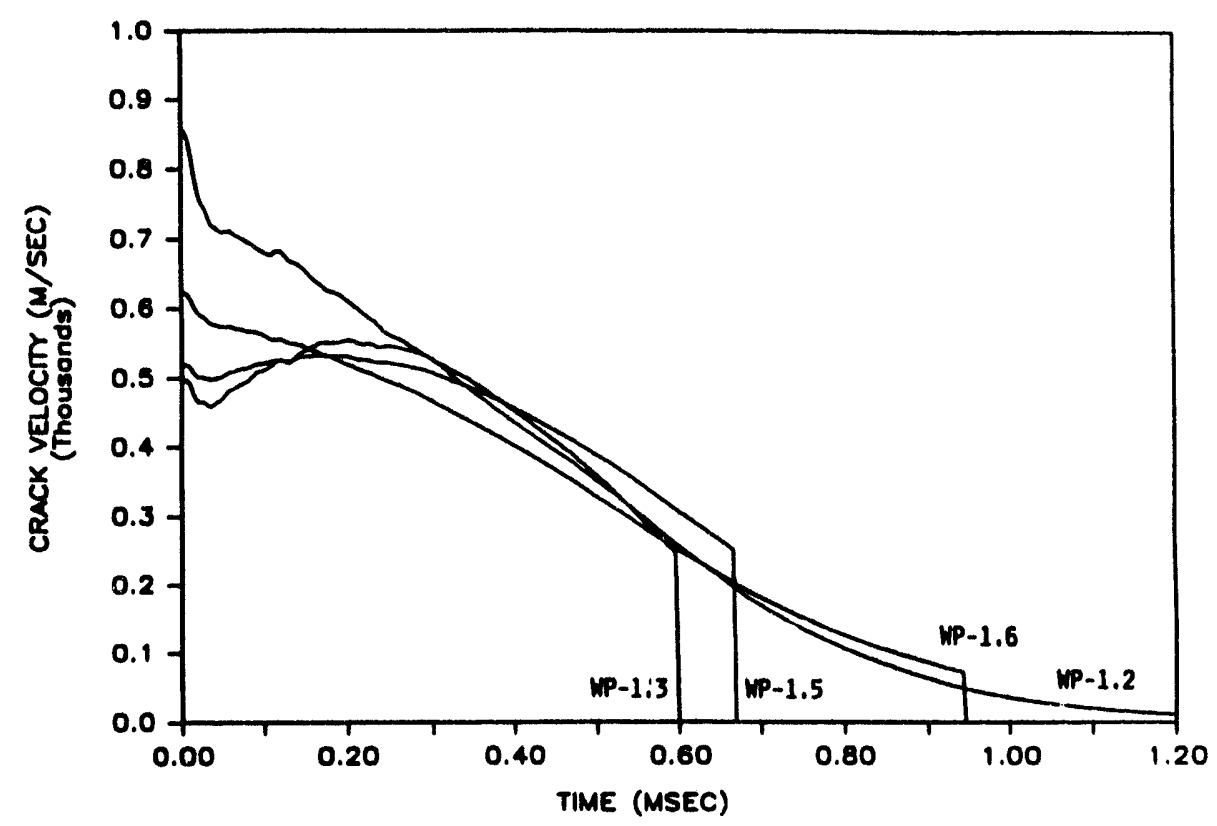

Figure 14 Crack-tip velocity histories predicted from application-mode analyses using new $\dot{a}-K_{1}-T$ relation

mode-values. The application-mode predictions for final crack length are closer to the experimental/generationmode values, with a mix of slight underestimation and overestimation and a maximum error equal to $7 \%$ (WP1.6). The computed dynamic-stress intensities at arrest in the application-mode analyses ranged within about $\pm 10 \%$ of the corresponding generation-mode analysis results.

The discrepancies between the experimental observations and the application mode analysis predictions based on the proposed $\dot{a}-K_{I}-T$ relation are much smaller than those from previous application-mode analyses using preliminary "best estimates" of the a- $\mathrm{K}_{\mathrm{I}}-\mathrm{T}$ relation for A 533 B steel: ${ }^{3}$

$$
K_{I}=K_{I A}+A\left(\dot{a}^{2}\right) .
$$

The arrest toughness $\mathrm{K}_{\mathrm{IA}}$ is given as

$$
\mathrm{K}_{\mathrm{IA}}=49.957+16.878 \mathrm{e}^{0.028738\left(\mathrm{~T}-\mathrm{RT}_{\mathrm{NDT}}\right)} \text {, }
$$

and the velocity parameter $A$ is given as

$$
\begin{gathered}
A=\left[329.70+16.25\left(T-R T_{N D T}\right)\right] \times 10^{-6} \\
T-R T_{\text {NDT }} \geq 13.9^{\circ} \mathrm{C}, \\
A=\left[121.71+1.2962\left(T-R_{\text {NDT }}\right)\right] \times 10^{-6} \\
T-R T_{\text {NDT }} \leq 13.9^{\circ} \mathrm{C},
\end{gathered}
$$

in which the units for $K_{I}, A, \dot{a}$, and $T$ are MPa- $m^{1 / 2}$, MPa-s ${ }^{2}-m^{-3 / 2}, \mathrm{~m} / \mathrm{s}$, and ${ }^{\circ} \mathrm{C}$, respectively. The arrest toughness vs temperature relation given in Eq. (6) is based upon data from small-scale tests and large-scale experiments that existed before the wide-plate test series, while the overall crack speed relation given in Eq. (7) is based upon experimental results for Japanese ship stecls tested at various temperatures. ${ }^{9}$ This original estimate of the à- $\mathrm{K}_{\mathrm{I}}-\mathrm{T}$ relation for A 533 B steel is compared against the new relation proposed in the present study in Fig. 15. Although both relations predict similar behavior at high $\mathrm{K}_{\mathrm{I}} / \mathrm{K}_{\mathrm{IA}}$ values, the new relation predicts much higher crack-tip velocitics at lower stress-intensity values.

Predicted results for crack-tip position, velocity, and $K_{I}$ vs time obtained from application-mode analyses based on the earlier preliminary à-K $\mathrm{I}-\mathrm{T}$ relation are shown in Figs. 11, 12 , and 13, respectively. Note that both sets of analyses are identical at initiation. Comparing the predictions based on the new [Eqs. (1)-(4)] and old [Eqs. (5)-(7)] $\dot{a}-\mathrm{K}_{\mathrm{I}}-\mathrm{T}$ relations, the computed crack-tip positions and velocities obtained using the new $\dot{\mathrm{a}}-\mathrm{K}_{\mathrm{I}}-\mathrm{T}$ relation are larger during the early portions of each crack event and srnaller later in each event and at arrest. The stress-intensity histories are remarkably similar for both sets of analyses, however, suggesting that the dynamic stress intensity is more directly related to the overall specimen loading and dynamics than to the details of the crack advance behavior, at least during the early stages of each event. 
Validation

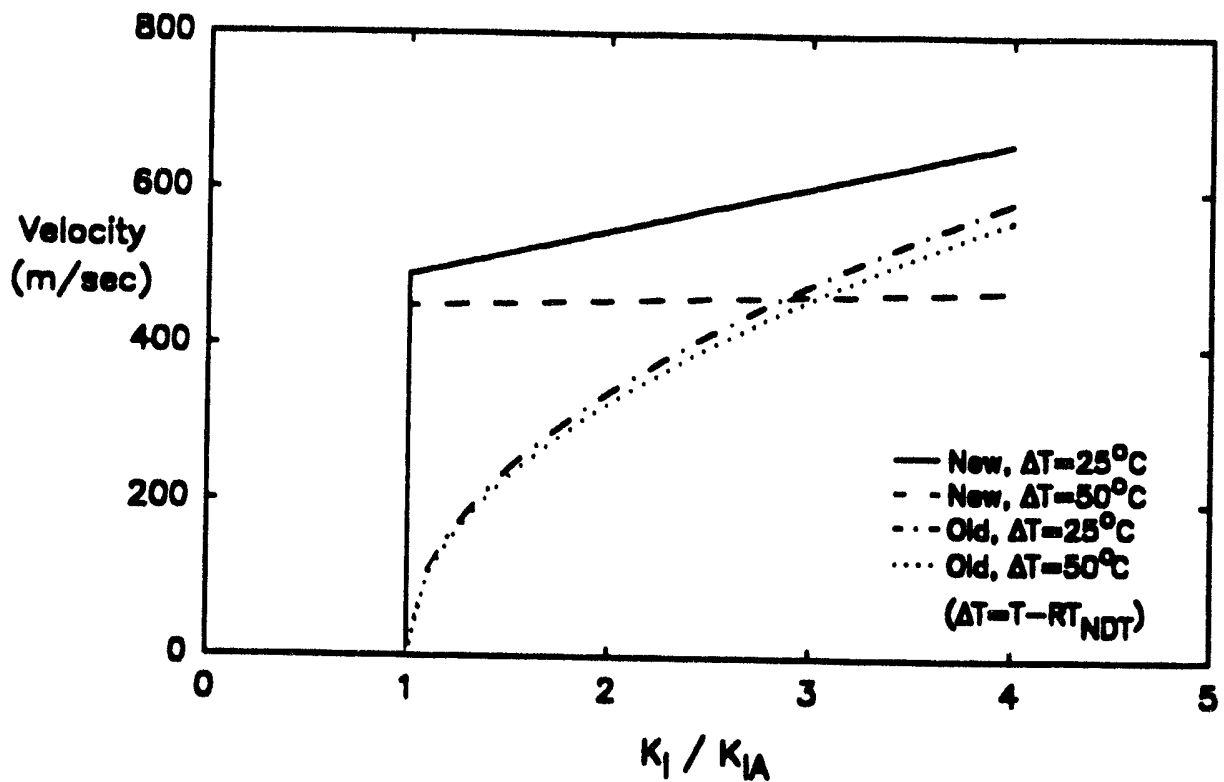

Figure 15 Comparison of proposed new [Eqs. (1)-(4)] and earlier estimated [Eqs. (5)-(7)] $\dot{a}-K_{I}-T$ relations for A 533 B steel

Predictions of conditions at arrest obtained from the application-mode analyses using the new [Eqs. (1)-(4)] and old [Eqs. (5)-(7)] $\dot{a}-K_{I}-T$ relations are compared in Table 4. Whereas the application-mode results based on the new $\dot{a}-K_{I}-T$ relation match the experimental/generation-mode analysis values reasonably closely, the application-mode results based on the old relation overestimate the arrest time, arrestcd length, and arrest toughness by up to 160 . 25 , and $30 \%$, respectively.

A serious flaw in the validation analyses described above is the fact that the test data being used to validate the pro- posed $\dot{\mathrm{a}}-\mathrm{K}_{\mathrm{I}}-\mathrm{T}$ relation are the same data that were used to derive it originally. However, later tests WP-1.7 and -1.8 on $15-\mathrm{cm}$-thick specimens are available as potential additional validation. Unfortunately, test WP-1.8 is unsuitable because of extensive tunneling and out-of-plane propagation of the crack. Test WP-1.7 did not display any of these ill-behaved characteristics, and the first fracture event has been analyzed in both generation and application modes. Details of test WP-1.7 are given in Ref. 4.

Figure 16 illustrates the crack-tip position and velocity vs time history for test WP-1.7 as determined by experimental

Table 4 Comparison of application-mode analysis prefictions using old and new $a-K_{I}-T$ relations

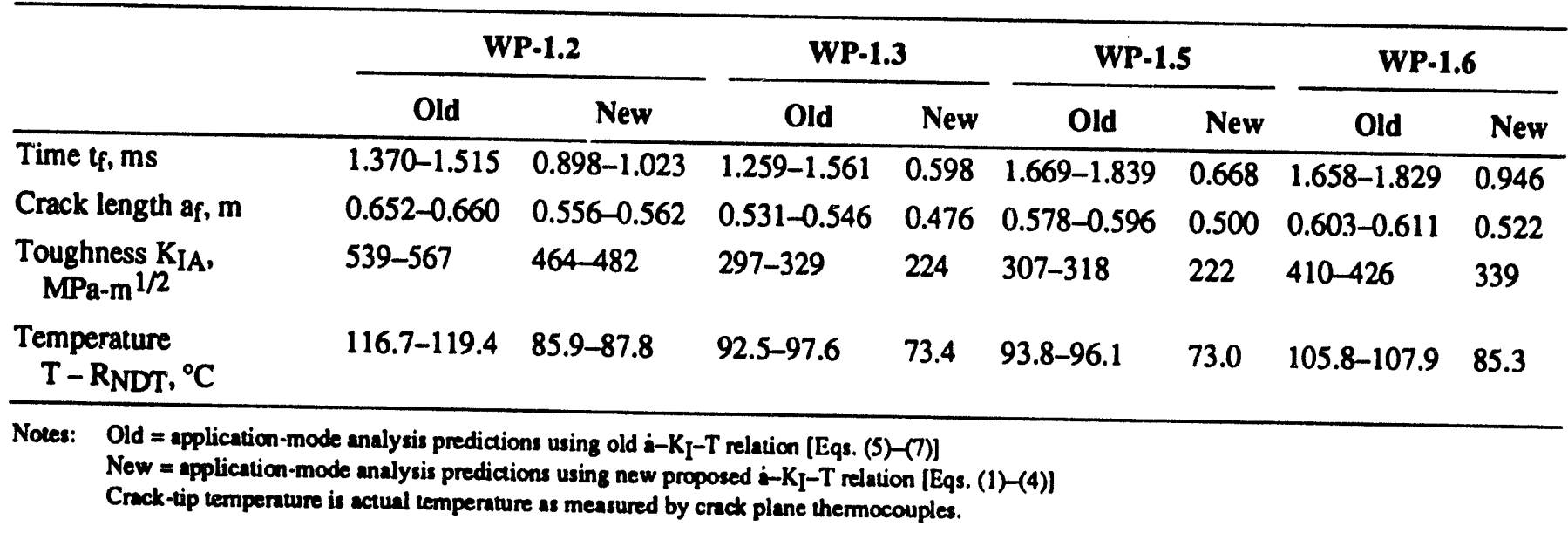


Validation
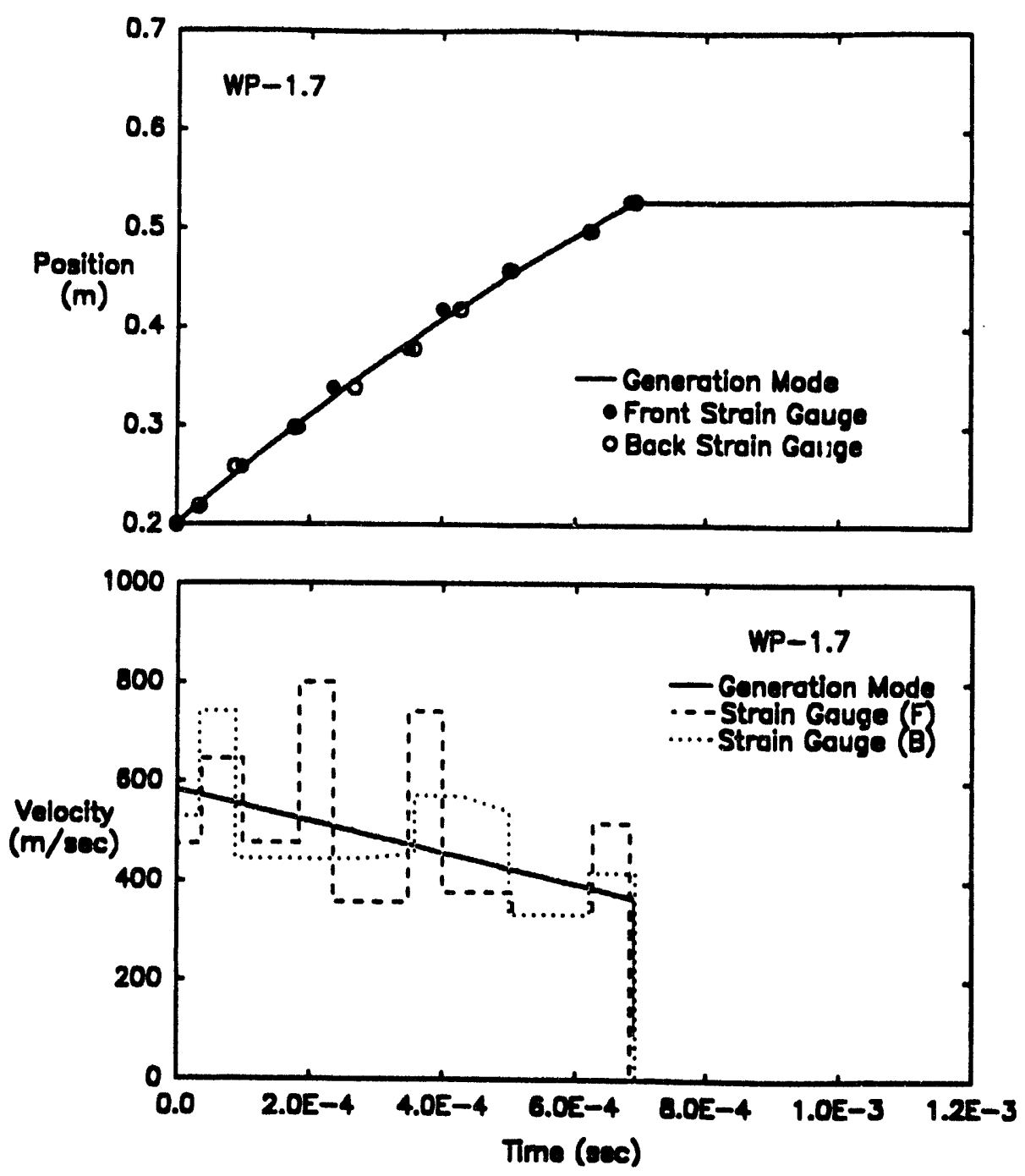

Figure 16 Crack-tip position and velocity vs time for test WP-1.7

measurement and by elastodynamic generation-mode analysis. The dynamic stress intensity vs time record computed in the generation-mode analysis is given in Fig. 17. The generation-mode analysis employed a cubic polynomial fit to the measured data:

$a=0.200+0.583 t-0.158 t^{2} \quad R^{2}=0.9993(m ; m s)$.

The agreement between the experimental data and the generation-mode calculations for the 0.15 -m-thick test WP-1.7 is similar to that seen earlier in the four $0.1-\mathrm{m}$ thick specimens.

Predictions of crack-tip position and crack velocity vs time from the application-mode analysis employing the new proposed $\dot{\mathfrak{a}}-\mathrm{K}_{\mathrm{I}}-\mathrm{T}$ rclation [Eqs. (1)-(4)] are compared to the generation-mode calculations in Fig. 18. Similar to the bchavior observed in test WP-1.2, the experimental data (and the generation-mode history derived from this experimental data) for test WP-1.7 indicate an abrupt arrest of the crack that is not modeled accurately by the applicationmode analysis. This discrepancy is sharply illustrated by the plots of crack-tip velocity vs time shown in Fig. 18. In the generation-mode analysis, the crack appears to abruptly arrest from a velocity of $\sim 370 \mathrm{~m} / \mathrm{s}(\sim 12 \%$ of shear wave velocity). In the application-mode analysis, the crack velocity decreases smoothly and propagation continues at very small velocities for well over $0.5 \mathrm{~ms}$. As before, arrest has been arbitrarily defined here to occur when the crack velocity drops below a threshold velocity of $\sim 1$ to $2 \%$ of shear wave velocity. Note that this definition yields an arrest point that is approximately equal to a simple extrapolation of the velocity trend during the middle portion of the event. 
Validation

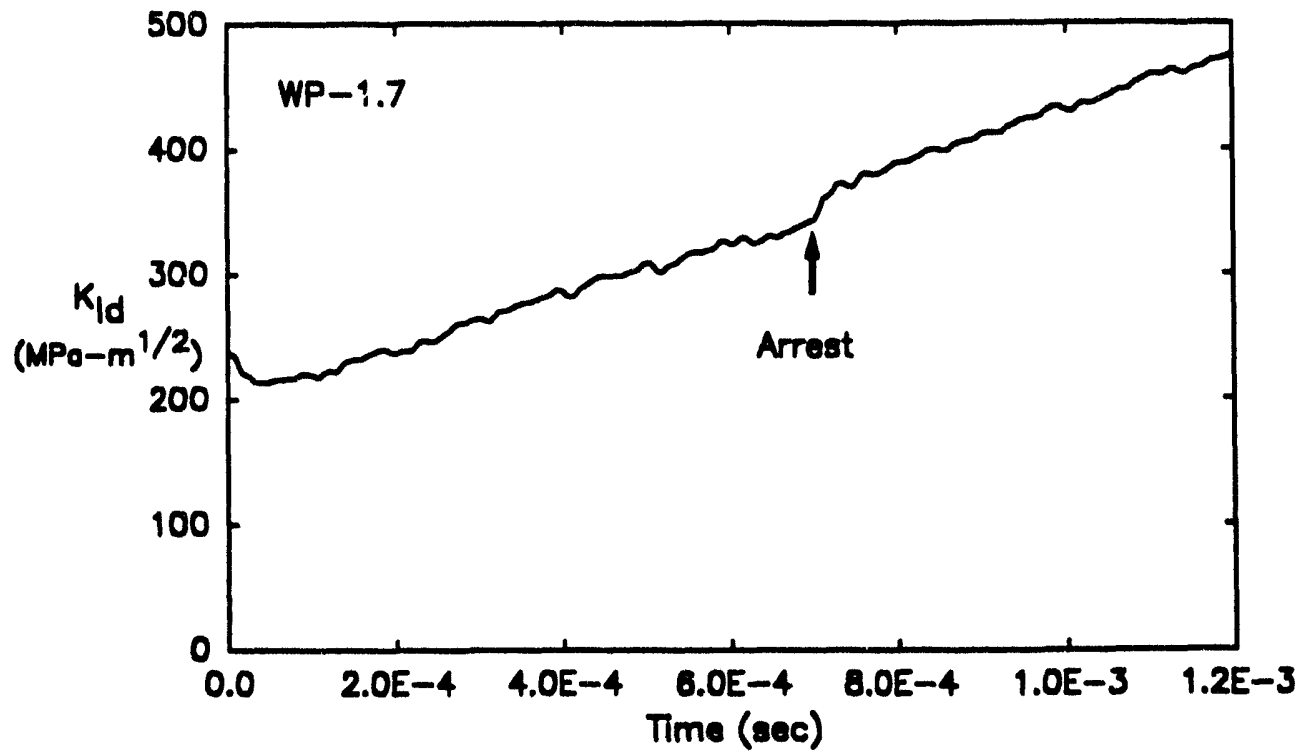

Figure 17 Generation-mode analysis prediction of dynamic stress intensity vs time for test WP-1.7

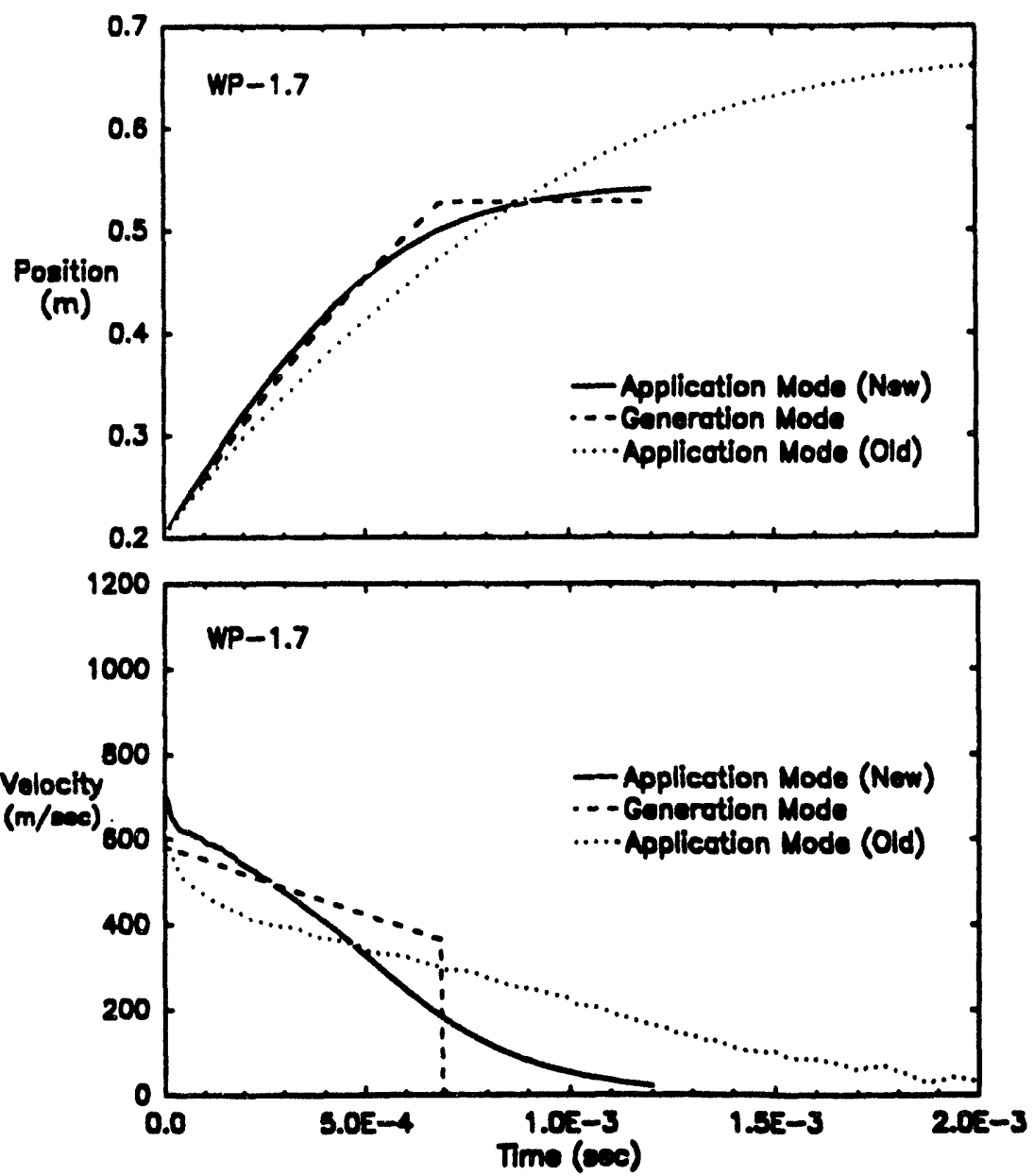

Figure 18 Crack-tip position and velocity histories predicted from generationand application-mode analyses of test WP-1.7 
Predictions of crack-tip position and crack velocity vs time from an application-mode analysis using the old [Eqs. (5)(7)] $\mathrm{a}-\mathrm{K}_{\mathrm{I}}-\mathrm{T}$ relation are also plotted in Fig. 18. The discrepancies between the application-mode predictions for test WP-1.7 based on the new and old crack speed relations are similar to those noted earlier for the four 0.1-m-thick specimens. Note that the period of predicted low-velocity crack advance is much more pronounced in the analysis using the old $\dot{a}-K_{I}-T$ relation.

Figure 19 depicts the dynamic stress-intensity factor vs time responses computed in the generation- and application-mode analyses of test WP-1.7. Despite the differences in the details of the crack-velocity behavior at arrest, all three analyses predict closely similar stress-intensity histories, at least during the first several hundred microseconds of response.
The measured and computed arrest conditions for test WP-1.7 are summarized in Table 5. The range of values for the application-mode predictions corresponds to the previously described definition of arrest at 1 to $2 \%$ of shear-wave velocity. The application-mode calculations based on the new $\dot{a}-K_{I}-T$ relation [Eqs. (1)-(4)] predict the arrested crack length to within $2 \%$ of the experimentally measured values. However, the arrest time is overestimated by $\sim 50 \%$ and the arrest toughness is overestimated by $-25 \%$. These results, although not as uniformly close as in the previous cases, are, nevertheless, a significant improvement in predictive capability. The application-mode analysis predictions for arrest time, arrested crack length, and dynamic arrest toughness, based upon the earlier hypothesized à-K $\mathrm{K}_{\mathrm{I}}-\mathrm{T}$ relation [Eqs. (5)-(7)], are 150, 25, and $55 \%$ greater, respectively, than the corresponding experimental/generation-mode analysis values for test WP-1.7.

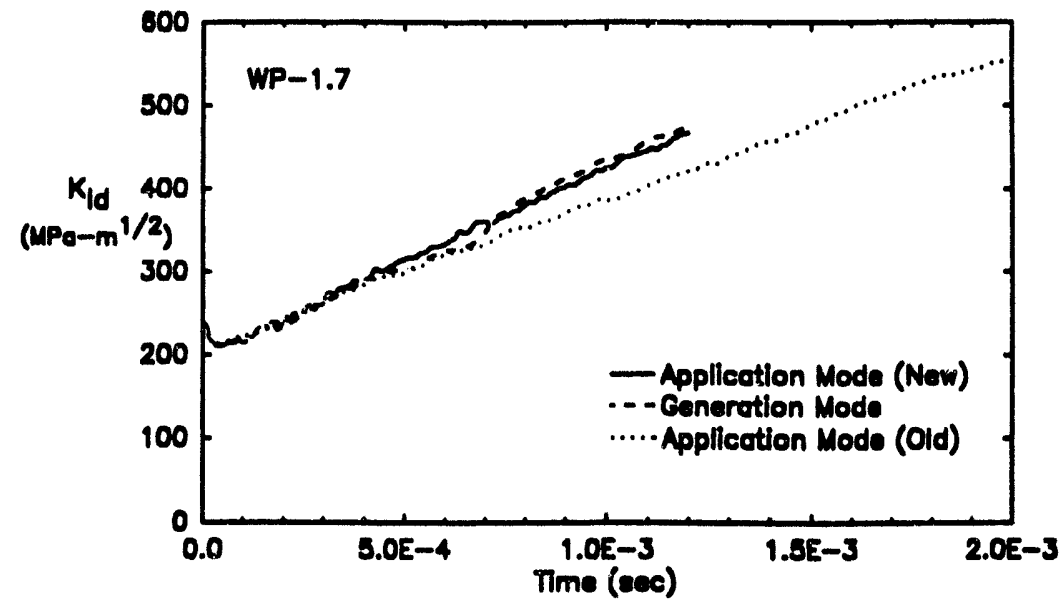

Figure 19 Dynamic stress-intensity histories predicted from generationand application-mode analyses of test WP-1.7

Table 5 Application-mode analysis predictions for test WP-1.7

\begin{tabular}{|c|c|c|c|}
\hline & EXP/GEN & APP/NEW & APP/OLD \\
\hline Time $t_{f}, m s$ & 0.692 & $0.955-1.114$ & $1.674-1.861$ \\
\hline Crack length $a_{f}, m$ & 0.528 & $0.531-0.538$ & $0.646-0.656$ \\
\hline $\begin{array}{l}\text { Toughness K } \\
\text { MPa-m }^{1 / 2}\end{array}$ & 341 & $414-418$ & $510-538$ \\
\hline $\begin{array}{l}\text { Temperature } \\
\mathrm{T}-\mathrm{R}_{\mathrm{NDT}},{ }^{\circ} \mathrm{C}\end{array}$ & 85.0 & $85.8-87.5$ & $114.5-116.8$ \\
\hline \multicolumn{4}{|c|}{$\begin{array}{l}\text { Notes: } \text { EXP }=\text { experimental results }\left(t_{f}, a_{f}, T-R T_{N D T}\right) \\
\text { GEN }=\text { generation-mode analysis results }\left(K_{I A}\right) \\
\text { APPNEW = application-mode analysis predictions using new proposed á- } K_{\mathrm{I}}-\mathrm{T} \text { relation [Eqs. (1)-(4)] } \\
\text { APP/OLD }=\text { application-mode analysis predictions using old a- } \mathrm{K}_{\mathrm{I}}-\mathrm{T} \text { relation }[\text { Eqs. (5)-(7)] } \\
\text { Crack-tip temperature is actual temperature as measured by crack plane thermocouples. }\end{array}$} \\
\hline
\end{tabular}




\section{Discussion}

The discrepancies between the predicted and measured/ computed values for arrest time and toughness in test WP-1.7 are likely due, in part, to the imprecise definition of the arrest point in the application-mode calculations and, in part, to inaccuracies in the proposed $\dot{\mathrm{a}}-\mathrm{K}_{\mathrm{I}}-\mathrm{T}$ relation in the high-temperature region where data are sparse. These problems need to be addressed further. Nonethi'ess, the proposed $\mathrm{a}-\mathrm{K}_{\mathbf{I}}-\mathrm{T}$ relation shows promise as an engincering tool until more refined estimates become available. Predictions of crack jumps, propagation times, and arrest toughness obtained using the proposed relation are significantly better than those obtained using the preliminary $\dot{a}-\mathrm{K}_{\mathrm{I}}-\mathrm{T}$ relation hypothesized for A 533 B steel [Eqs. (5)-(7)].

An important question in the derivation of the proposed $\dot{a}-K_{I}-T$ relation is the validity of elastodynamic calculations for the wide-plate test configuration. Significant viscoplastic yielding may be expected in some of the more highly loaded tests. Results to date have bcen unclcar, however. Bass et al. ${ }^{10}$ report that generation-mode viscoplastic analyses of test WP-1.2 (the most highly loaded specimen in the WP-1 series) predict "pseudo" $\mathrm{K}_{\mathrm{I}}$ values at arrest that are $40 \%$ less than the corresponding linearly elastic result. Substantial mesh refinement dependencies and other questions, however, make this viscoplastic analysis result difficult to interpret. Taking; a different approach to the plasticity effect, Fields and deWit ${ }^{11}$ examined the posttest thickness reduction of test WP-1.2 and concluded that significant plastic yiclding occurred only after the initial arrest of the crack.

Dahlbcrg and Nilsson ${ }^{12}$ have suggested theoretical guidelines for determining the validity of the small-scale yield- ing assumption for dynamic fracture of viscoplastic materials:

$$
\begin{aligned}
& \frac{2 \mathrm{R}}{\dot{\mathrm{a} K}}\left|\frac{\delta \mathrm{K}}{\delta \mathrm{t}}\right| \ll 1, \\
& \frac{2 \mathrm{R}}{\dot{\mathrm{a}}^{2}}\left|\frac{\delta^{2} \mathrm{a}}{\delta \mathrm{t}^{2}}\right| \ll 1,
\end{aligned}
$$

in which $R$ is the radius of the inelastic zone. Taking test WP-1.7 as typical for the WP-1 serics and considering the first fracture event, Eqs. (9) and (10), respectively, evaluate to 0.04 and 0.05 just after initiation, 0.27 and 0.17 at the midpoint of the first event, and 0.23 and 0.30 just before arrest. This suggests that even though the assumption of small-scale yielding may not be strictly valid, it is at least reasonable as a first approximation. This is particularly justified at present, given the many unanswered questions regarding a suitable viscoplastic fracture criterion.

Clearly, the validation analyses performed to date are not sufficient to address the question of the uniqueness of the proposed $\dot{a}-K_{I}-T$ relation as a material property. This is an issue of continuing controversy (e.g., Refs. 13-15). A definitive answer for A 533 B steel will require high-quality test data from a variety of specimen geometric and lo: ig configurations. The wide-plate tests provide some of uicse data. Medium- and small-scale tests currently under way in the HSST Program will provide additional data both for validating the proposed $\dot{a}-K_{I}-T$ relation and for establishing its uniqueness.

\section{Conclusion}

A methodology for inferring $\dot{a}-\mathrm{K}_{\mathrm{I}}-\mathrm{T}$ relations from instrumented dynamic-fracture tests has been developed and applied to data from four large-scale wide-plate experiments on A 533 B steel. Application-mode analytical predictions based on this proposed $\mathrm{a}-\mathrm{K}_{\mathrm{I}}-\mathrm{T}$ relation are within $7 \%$ of experimentally measured arrested crack lengths and within $50 \%$ of experimentally measured arrest times for the wide-plate specimen geornetry. These results are significantly better than earlier application-mode analyses in which predicted values for arrested crack length and arrest times by 25 and $160 \%$, respectively. Although additional validation of the proposed $\mathrm{a}-\mathrm{K}_{\mathrm{I}}-\mathrm{T}$ rclation must be performed over a wider range of specimen geometries and test conditions, the proposed relation shows promise as a tool for estimating dynamic crack jumps, propagation times, and arrest toughness. 


\section{References}

1. R. D. Cheverton et al., "Fracture Mechanics Data Deduced from Thermal-Shock and Related Experiments with LWR Pressure Vessel Material," Journal of Pressure Vessel Technology 105, 102-110 (May 1983).*

2. R. H. Bryan et al., "The Heavy-Section Steel Technology Pressurized-Thermal-Shock Experiment, PTSE-1," Eng. Fract. Mech. 23 (1), 81 -97 (1986). *

3. D. J. Naus et al., Martin Marietta Energy Systems, Inc., Oak Ridge Natl. Lab., "Crack-Arrest Behavior in SEN Wide Plates of Quenched and Tempered A 533 Grade B Steel Tested Under Nonisothermal Conditions," USNRC Report NUREG/CR-4930 (ORNL-6388), $1987 . \dagger$

4. D. J. Naus et al., Martin Marietta Energy Systems, Inc., Oak Ridge Natl. Lab., "High-Temperature CrackArrest Behavior in 152-mm-Thick SEN Wide Plates of Quenched and Tempered A 533 Grade B Class 1 Steel," USNRC Report NUREG/CR-5330 (ORNL/TM-11083), 1989. †

5. C. W. Schwartz et al., University of Maryland for Martin Marietta Energy Systems, Inc., Oak Ridge Natl. Lab., "SAMCR: A Two-Dimensional Dynamic Finite Element Code for the Stress Analysis of Moving Cracks," USNRC Report NUREG/CR-3891

(ORNL/Sub/79-7778/3), 1984. †

6. B. R. Bass, C. E. Pugh, and H. K. Stamm, "Dynamic Analyses of a Crack Run-Arrest Experiment in a Nonisothermal Plate," Pressure Vessel Components Design and Analysis 4, ASME PVP 98-2, 175-184 (1985). *

7. ADINA Engineering Inc., "ADINA: A Finite Element Program for Automatic Dynamic Incremental Nonlinear Analysis," 71 Elton Avenue, Watertown, MA 02172, 1984.
8. A. Pellissier-Tanon, P. Sollogoub, and B Houssin, "Crack Initiation and Arrest in an SA 508 Class-3 Cylinder Under Liquid Nitrogen Thermal-Shock Experiment," pp. 132-142 in Transactions of the 7th International Conference on Structural Mechanics in Reactor Technology, Vols. G and H, Paper G/F 1/8, 1983. +

9. T. Kanazowa et al., "Study on Fast Fracture and Crack Arrest," Experimental Mechanics 21, 78-88 (1981). *

10. B. R. Bass et al., "Applications of ADINA to Viscoplastic-Dynamic Fracture Mechanics Analysis," Computers and Structures 32,815-824 (1989). *

11. R. J. Fields and R. deWit, "Plastic Zone Formation Around an Arresting Crack," Int. J. Fract. (1989).

12. L. Dahlberg and F. Nilsson, "Some Aspects of Testing Crack Propagation Toughness," p.281 in Proceedings, International Conference on Dynamic Fracture Toughness, The Welding Institute, Cambridge, England, 1976. ${ }^{\dagger}$

13. J. W. Dally, W. L. Fourney, and G. R. Irwin, "On the Uniqueness of the Stress Intensity Factor-Crack Velocity Relationship," Int. J. Fract. 27, 159-168 (1985). *

14. W. G. Knauss and K. Ravi-Chandar, "Some Basic Problems in Stress Wave Dominated Fracture," Int. J. Fract. 27, 127-144 (1985).*

15. A. J. Rosakis and A. T. Zehnder, "On the Dynamic Fracture of Structural Metals," Int. J. Fract. 27, (3-4), $169-186(1985) .^{*}$

\footnotetext{
* Available in public technical libraries.

† Available for purchase from National Technical Information Service, Springfield, VA 22161
} 


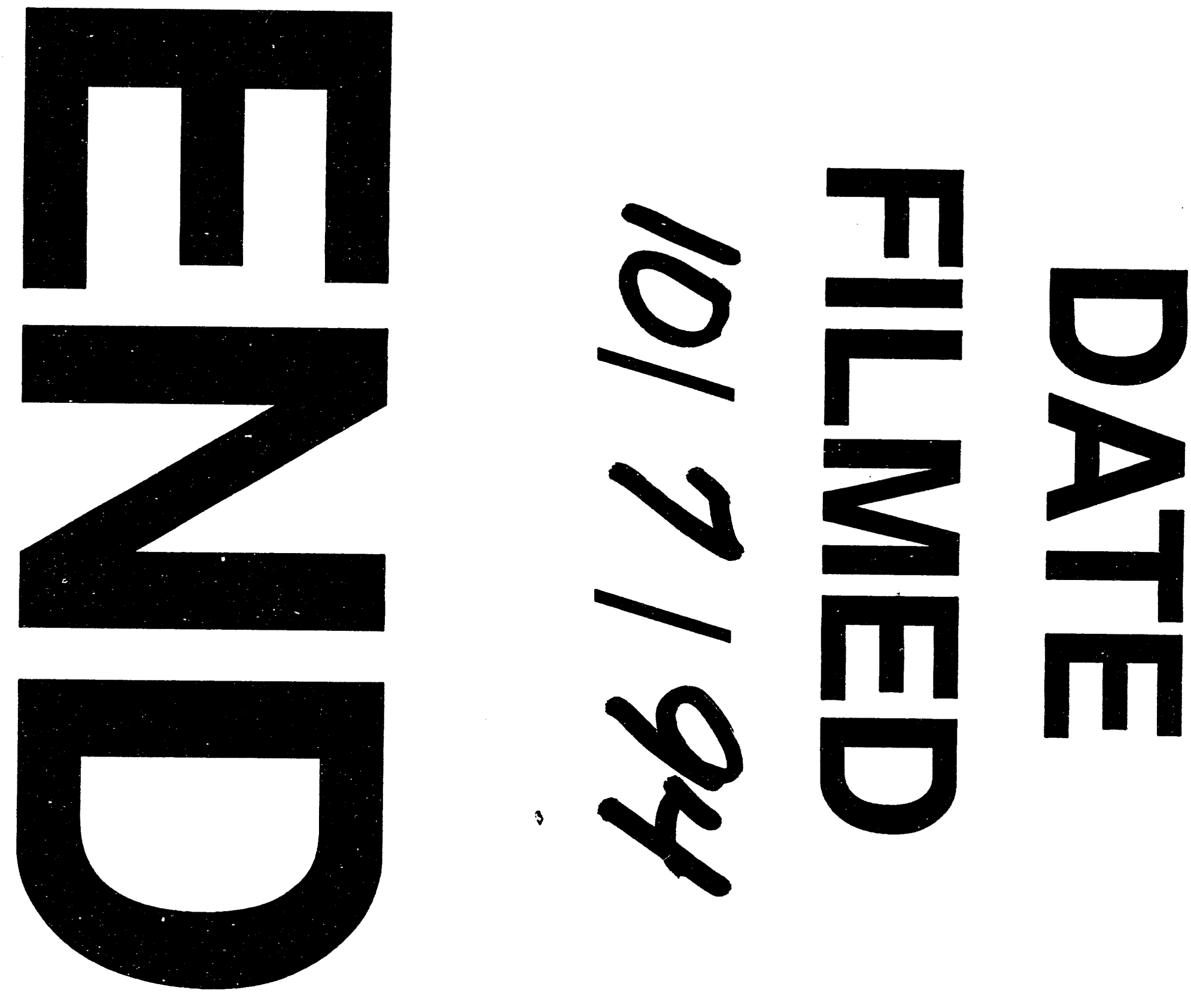
